This item was submitted to Loughborough's Research Repository by the author.

Items in Figshare are protected by copyright, with all rights reserved, unless otherwise indicated.

\title{
Three dimensional printed electronic devices realised by selective laser melting of copper/high-density-polyethylene powder mixtures
}

\section{PLEASE CITE THE PUBLISHED VERSION}

https://doi.org/10.1016/j.jmatprotec.2017.11.020

\section{PUBLISHER}

(C) Elsevier

VERSION

AM (Accepted Manuscript)

\section{PUBLISHER STATEMENT}

This paper was accepted for publication in the journal Journal of Materials Processing Technology and the definitive published version is available at https://doi.org/10.1016/j.jmatprotec.2017.11.020.

\section{LICENCE}

CC BY-NC-ND 4.0

\section{REPOSITORY RECORD}

Hou, Shuai, Siyuan Qi, David Hutt, John Tyrer, Mulan Mu, and Zuoxin Zhou. 2019. "Three Dimensional Printed Electronic Devices Realised by Selective Laser Melting of Copper/high-density-polyethylene Powder Mixtures". figshare. https://hdl.handle.net/2134/27926. 
Three Dimensional Printed Electronic Devices Realised by Selective Laser Melting of Copper/High-Density-Polyethylene Powder Mixtures

Shuai Hou ${ }^{\text {a,b,* }}$, Siyuan Qi ${ }^{b}$, David A. Hutt ${ }^{\text {a }}$, John R. Tyrer ${ }^{a}$, Mulan Mu ${ }^{c}$, Zuoxin Zhou ${ }^{c}$

${ }^{a}$ Wolfson School of Mechanical, Electrical and Manufacturing Engineering, Loughborough University, Loughborough, LE11 3TU, United Kingdom

b The Manufacturing Technology Centre, Ansty Park, Coventry, CV7 9JU, United Kingdom

${ }^{\mathrm{c}}$ WMG, University of Warwick, Coventry, CV4 7AL, United Kingdom

*Corresponding author: Shuai Hou

Telephone number: $\quad$ +44 7760837189

E-mail address: $\quad$ shuaihou87@gmail.com

Address: Wolfson School of Mechanical, Electrical and Manufacturing Engineering, Loughborough University, Loughborough, LE11 3TU, United Kingdom 


\section{Abstract}

A manufacturing process with the capability to integrate electronics into 3D structures is of great importance to the development of next-generation miniaturised devices. In this study, Selective Laser Melting (SLM) was used to process copper/high-density-polyethylene (HDPE) powder mixtures to build conductive tracks in a 3D circuit system. The effects of copper/HDPE volume ratio, laser input power and scanning speed on the resistivity of $\mathrm{CO}_{2}$ laser processed tracks were investigated. The resistivity of the tracks decreased from $26.6 \pm 0.6 \times 10^{-4} \Omega \mathrm{cm}$ to $1.9 \pm 0.1 \times 10^{-4} \Omega \mathrm{cm}$ as the copper volume ratio increased from $30 \%$ to $60 \%$. However, further increasing the copper ratio to $100 \%$ resulted in poor conductivity. The lowest resistivity was achieved with an input power of $20 \mathrm{~W}$ and scanning speed of $80 \mathrm{~mm} / \mathrm{s}$. Additionally, processing using single-track-scanning and raster-scanning programs was compared; the overall energy distribution on the surface was more uniform using a rasterscanning program, which further reduced the resistivity to $0.35 \pm 0.04 \times 10^{-4} \Omega \mathrm{cm}$. Based on the results, a 3D multi-layered circuit system was manufactured with the HDPE as the substrate/matrix material and copper/HDPE mixture as the conductive-track material. This circuit system was successfully manufactured, demonstrating the possibility of using SLM technology to manufacture dissimilar materials towards 3D electronic applications. 


\section{Graphical abstract}
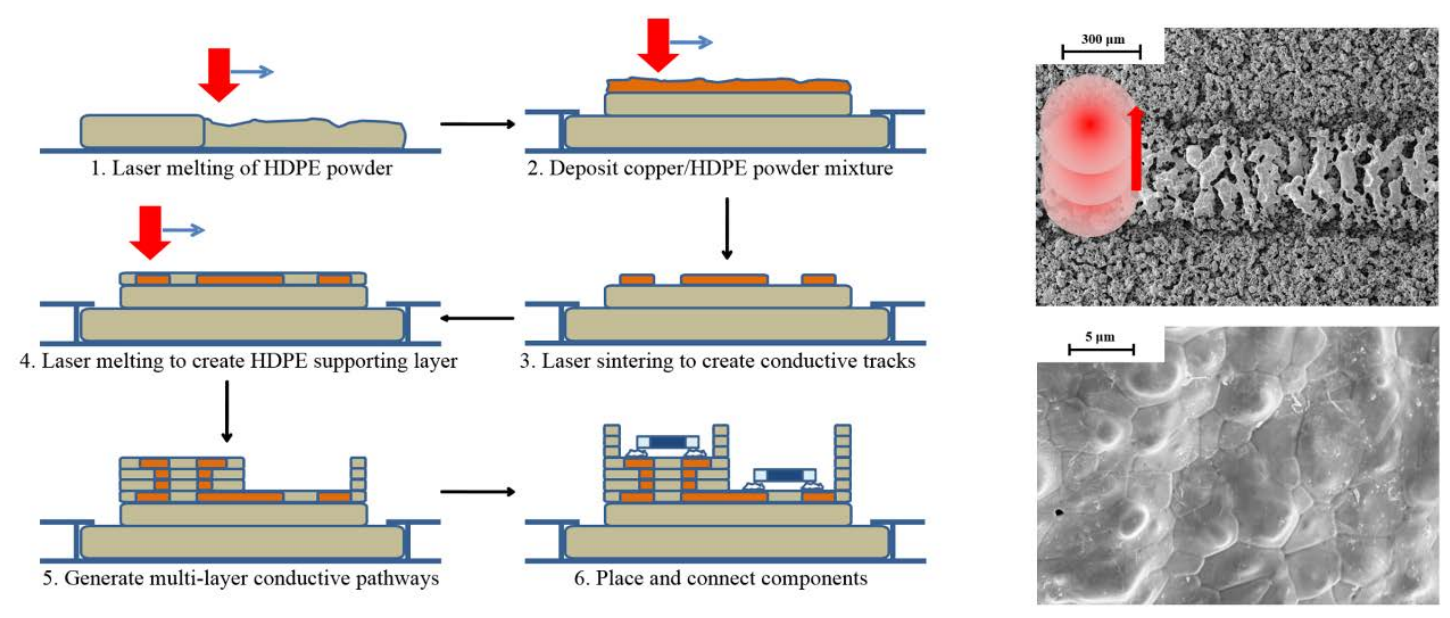

\section{Keywords}

Selective laser melting, Additive Manufacturing, HDPE, copper, resistivity, 3D electronics

\section{Introduction}

A printed circuit board (PCB) is typically a two-dimensional (2D) system that interconnects electronic components using conductive tracks laminated onto a dielectric substrate. However, the increasing demands of small-scale electronic devices, such as mobile communications, smart home appliances and military equipment, require miniaturization that can be further achieved by moving towards three-dimensional circuit configurations with simultaneously improved performances. Double-sided and multi-layered PCBs are widely used to reduce the circuit volume and components have also been embedded within the layers to save space on the surface, but these still retain a largely 2D (2.5D) format (Etienne and Sandborn, 2007). To move towards 3D devices, flexible substrates have been used that enable circuits to fold around/inside other parts of an assembly (Siegel et al., 2010). In addition, moulded interconnect devices (MIDs) have been created that involve the deposition of circuit patterns on the surface of injection moulded parts with non-planar shapes that, for example, 
form the structure of the product casing (Chen and Young, 2013). However, many of the currently available manufacturing processes for PCBs have long production cycles due to the requirement for tooling and involve subtractive processes with associated waste, for example, from photolithography and metal etching steps, or may use solvents that are incompatible with some polymer substrates (Ko et al., 2007).

With the growing demand to integrate electronics within the fabric of products, that may themselves have novel form factors, there is an ever increasing need to develop technologies able to embed electronic circuitry directly into a wide range of materials and structures. Additive Manufacturing (AM) allows the creation of 3D objects by forming successive layers from pre-designed digital models. This technology has already transformed the concept of conventional manufacturing production and made significant impacts on various industries including aerospace, medical implants, automotive, construction and art design (D'aveni et al., 2013). Due to its ability to manufacture complex geometries, AM has the potential to produce 3D electronic devices by depositing conductive tracks within a 3D dielectric matrix. This process is also environmentally friendly with minimum manufacturing loss produced. Previous studies used stereolithography (SLA) to build substrates with slots designed for the integration of electrical components that were subsequently connected using a conductive paste deposited by micro dispensing (Lopes et al., 2012). By repeating the cycle of these two processes it was possible to manufacture a complete 3D embedded circuit. As an alternative to conductive paste deposition, a more flexible AM technology is drop-on-demand (DOD) inkjet printing, which deposits droplets of polymer solution (Ko et al., 2008) or nano-metal suspension (Cui et al., 2010) onto a substrate. This technique is only suitable for 2D or micro-3D circuit printing due to the small droplet size and the restriction of ink viscosity (Park et al., 2007). However, with both pastes and inks, an additional thermal curing step using, for example, an oven, hotplate or laser, is usually required to sinter the nano-metal 
deposits (Mun et al., 2012) or cure the adhesive pastes (Sanchez-Romaguera et al., 2008) and this can limit the range of suitable substrate materials.

A key challenge in 3D printing of embedded electronic devices is to develop a process that is capable of manufacturing cost effective metallic conductors, can be integrated with the buildup of 3D dielectric material and be compatible with the wide range of potential substrate materials and form factors demanded by the end applications. Selective Laser Melting (SLM) is a laser-based computer controlled additive manufacturing technology used to build 3D objects with complex geometries from powders. SLM has the potential to manufacture dissimilar materials by spreading powder layers with different materials during different stages of the process (Liu et al., 2014). In the study reported here, SLM was used to create conductive tracks from a copper and high-density-polyethylene (HDPE) powder mixture, which was simultaneously incorporated within a HDPE dielectric matrix to form an overall 3D embedded circuit architecture. Due to its monochromatic and coherent properties, the laser can be used to generate highly localised heat to create desirable patterns during manufacturing and in this study, a low cost $\mathrm{CO}_{2}$ laser was utilized as it was found to be capable of processing both the copper and HDPE powder materials. To avoid the use of high cost nanoscale metals, such as gold and silver, micron scale copper powder was selected in this study to create the conductive tracks. A continuous pathway of particles is required so that the electrons can move freely between them to offer high conductivity. However, the oxide formed on the copper surface can create a highly resistive barrier between particles and therefore a pre-treatment of the powder surface was carried out to remove the oxide layer and restrict re-oxidation by the application of a self-assembled monolayer (SAM) organic coating (Hutt and Liu, 2005). This facilitates the use of the copper particles in air and, during exposure to the laser beam, the coating is believed to be displaced enabling clean copper surfaces to come in to contact. Good adhesion between the conductive pattern material and 
the dielectric matrix is important to support the structures and it was proposed that this can be achieved using the same polymer binder to establish the matrix and the supporting structure for the conductive particles. Nylon-12 (or polyamide-12) is the most commonly used polymer material in SLM processing due to its broad 'super-heating region' (Caulfield et al., 2007). However, nylon products manufactured using SLM usually have a relatively high porosity of between 5-10\% due to high water content (Goodridge et al., 2012), which could present long term reliability issues. Therefore, an HDPE powder was used in this study as the substrate material as well as the binding material within the conductive track (Bai et al., 2016). A systematic analysis of the effects of copper/HDPE ratio, laser input power, scanning speed, and scanning program on the electrical conductivity and microstructure of the resulting conductive tracks was carried out in order to understand the mechanism of powder melting and consolidation during the laser process. The outcome of this study will contribute to the manufacturing of functional 3D electronics from dissimilar materials using AM technology.

\section{Materials and Methods}

The as-received copper powder (Sigma-Aldrich, UK) used in this study had an average particle size of $10 \mu \mathrm{m}$ and the HDPE powder (HMHDPE75A, Goonvean Fibres, UK) had an approximate particle size of $12 \sim 22 \mu \mathrm{m}$. A preliminary study had demonstrated good flowability for this particle size combination during SLM processing (data not reported). The copper oxide was removed by etching and subsequently a self-assembled-monolayer (SAM) coating of Octadecanethiol (ODT, HS- $\left(\mathrm{CH}_{2}\right)_{17}-\mathrm{CH}_{3}$, Sigma-Aldrich, UK) was used to provide an efficient protection from oxidation for the copper (Qi et al., 2013). After the SAM coating was applied the powder was stored in a freezer to further reduce the rate of re-oxidation. Xray photoelectron spectroscopy (XPS) (Thermo Scientific K-Alpha) was used to identify the oxidation conditions of the copper particles before and after SAM coating. Monochromatic 
$\mathrm{Al} \mathrm{K \alpha}$ radiation was used throughout the experiments and a flood gun was used to prevent peak shifts due to charging.

SAM coated copper powder was mixed with HDPE powder at the following volume contents: 30, 40, 50, 60, 70, and 100\%, using a centrifugal mixer (SpeedMixer, DAC 150 FVZ-K, FlackTek Inc, Germany) at 2000 rpm for 2 minutes. A bespoke manufactured reservoir with an adjustable platform as the central part was used to create a powder bed (Figure 1 (a)). The movement of the platform was controlled using a threaded bar and the displacement was measured with a dial gauge, with a resolution of $10 \mu \mathrm{m}$. A small acrylic box with an opening for the laser was used to cover the sample and Argon was flowed into the box during the process to protect the powders from oxidation.

A Gaussian beam, Synrad Firestar $100 \mathrm{~W} \mathrm{CO}_{2}$ laser, wavelength $10.6 \mu \mathrm{m}$ with a pulse width modulation of $20 \mathrm{kHz}$ was used to process both the HDPE and copper powders. An HDPE substrate was first generated by scanning across a 100\% HDPE powder bed. After processing one layer of HDPE at a condition of $10 \mathrm{~W}$ power, $240 \mathrm{~mm} / \mathrm{s}$ scanning speed, and $0.2 \mathrm{~mm}$ scan spacing, the platform was moved down $150 \mu \mathrm{m}$ and a second layer of HDPE powder was spread over the previous layer and laser processed. The HDPE substrate was completed after five layers of HDPE powders were deposited in this way. Thereafter, a layer (150 $\mu \mathrm{m}$ thick) of mixed copper/HDPE powder was spread over the HDPE substrate (Figure 1 (b)). The mixed materials were exposed to the Gaussian beam that followed a straight path to form a single layer conductive track, after which the surrounding loose powder was removed. Different laser power inputs and scanning speeds were investigated for the SLM process in the range of $10 \mathrm{~W}$ to $40 \mathrm{~W}$ and 80 to $120 \mathrm{~mm} / \mathrm{s}$ respectively. Additionally, a raster-scanning program was used to compare with the single-line-scanning program. It scanned a track following a zig-zag pattern $(0.2 \mathrm{~mm}$ width and $0.1 \mathrm{~mm}$ scan spacing) perpendicular to the direction of the single-line scan as shown in Figure 1. Samples that were manufactured under 
different compositional and processing conditions are hereafter referred to in this paper with a system that includes: laser beam profile (G-Gaussian) - scanning program (s-single line scan, r-raster scan) - copper/HDPE powder ratio - laser input power (W) - scanning speed $(\mathrm{mm} / \mathrm{s})$. For example, G-s-3/7-20-120 refers to a sample manufactured using a Gaussian beam, single-line scanning program, 3/7 copper/HDPE ratio, $20 \mathrm{~W}$ input power and 120 $\mathrm{mm} / \mathrm{s}$ scanning speed.

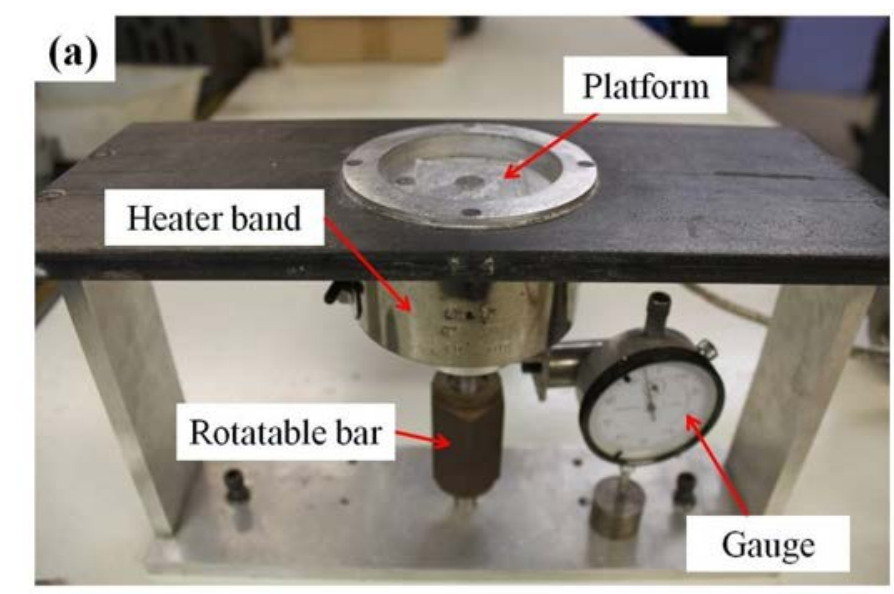

Raster scan

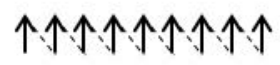

(b)
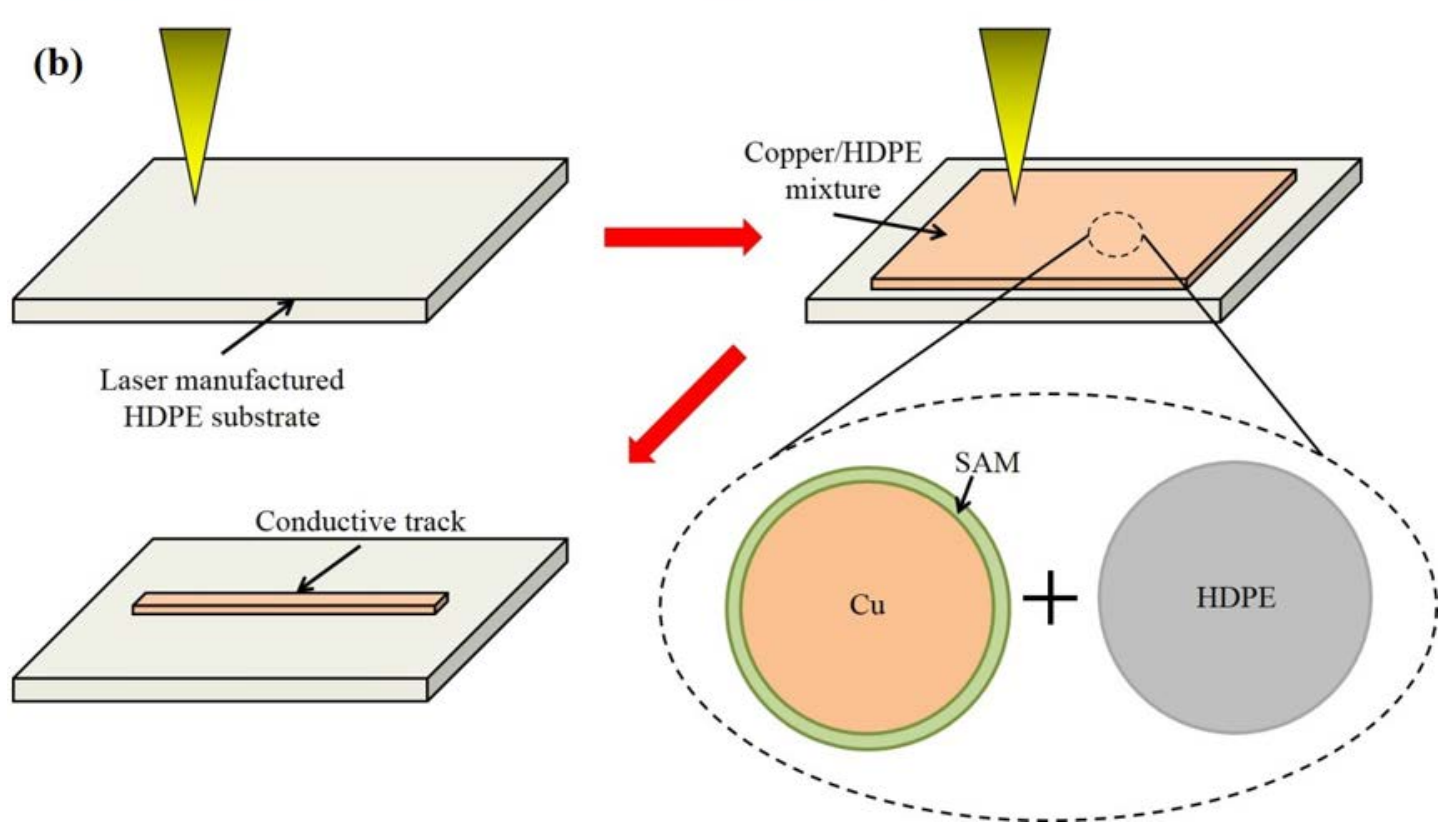

Figure 1: (a) The build platform for the SLM process and (b) schematic diagrams of the SLM of copper/HDPE powder to form a conductive track on an HDPE substrate. The mixture of HDPE and SAM coated copper particles in the powder bed is highlighted. A diagram of the laser path for the single line and raster scan patterns is also included. 
In some of the laser melting experiments, an infrared (IR) thermal camera (Thermovision A40m, FLIR, USA) was set up to monitor the surface temperature of the sample at a recording rate of $50 \mathrm{fps}$; the emissivity of HDPE white powder was set as 0.9. However, since the wavelength of the $\mathrm{CO}_{2}$ laser is in the spectral range of the thermal camera (7.5-13 $\mu \mathrm{m}$ ), a wide band pass filter (SWBP-8486-000816, Northumbria Optical Coatings Ltd., UK) was selected to block the $10.6 \mu \mathrm{m}$ beam.

Scanning Electron Microscopy (SEM) (Leo 4401530 VP, Carl Zeiss, Germany) was used to show both the surface and internal microstructure of the conductive tracks at an operating voltage of $3.0 \mathrm{kV}$. The cross-section of the tracks was revealed by cooling them with liquid nitrogen and then fracturing them. Samples were mounted on $12.5 \mathrm{~mm} \times 1 \mathrm{~mm}$ aluminium discs using carbon tape and were subsequently sputtered with a 10-20 nm thick coating of gold on the surface to reduce charging effects.

A 4-point probe technique was used to measure the resistance of the conductive tracks (measurement length $1 \mathrm{~cm}$ ) (Mironov et al., 2007) and this was converted to resistivity using the cross-section area of the track that was determined from its SEM image. To do this, a threshold level for the SEM image was determined from the greyscale histogram, which was generated using ImageJ software (National Institutes of Health, USA). The threshold level was selected in the position that best separated copper/HDPE materials from the substrate material since they exhibited distinct peaks within the histogram. Thereafter the cross-section was isolated in the image and its area was thus determined. 


\section{Results and Discussion}

\subsection{Powder Material Analysis}

The surface condition of the copper powder was examined by XPS (Figure 2). According to the XPS spectra, the as-received (untreated) copper powder showed the expected $\mathrm{Cu} 2 \mathrm{p}_{3 / 2}$ and $2 \mathrm{p}_{1 / 2}$ peaks at around $933 \mathrm{eV}$ and $953 \mathrm{eV}$ respectively that are characteristic of $\mathrm{Cu}(0)$ or $\mathrm{Cu}(\mathrm{I})$ oxidation states. However, these peaks displayed significant shoulders on the high binding energy side due to additional $\mathrm{Cu}(\mathrm{II})$ oxidation states and broad satellite features at $\sim 944 \mathrm{eV}$ were clearly observed, also due to $\mathrm{Cu}(\mathrm{II})$ states. A strong $\mathrm{O}$ 1s peak was seen, further indicating the significant oxidation of the untreated copper surface as expected (Tahir and Tougaard, 2012) (Figure 2 (a, b)). After application of the ODT SAM coating, the C 1s peak (Figure 2 (c)) became sharp compared to the broad features observed before treatment and S was detected (Figure $2(\mathbf{d})$ ) which was in agreement with earlier work on SAM coated metals (Laibinis et al., 1992). Most significantly, the O 1s peak almost disappeared after the copper was treated and the $\mathrm{Cu} 2 \mathrm{p}$ peaks also became sharp with no evidence of the previous $\mathrm{Cu}(\mathrm{II})$ satellites (Figure 2 (a, b)). The XPS spectra therefore indicated that the copper oxide was successfully removed by etching and the SAM was coated on the copper particles, which was an effective approach to further protect the copper from oxidation during the subsequent SLM process. 


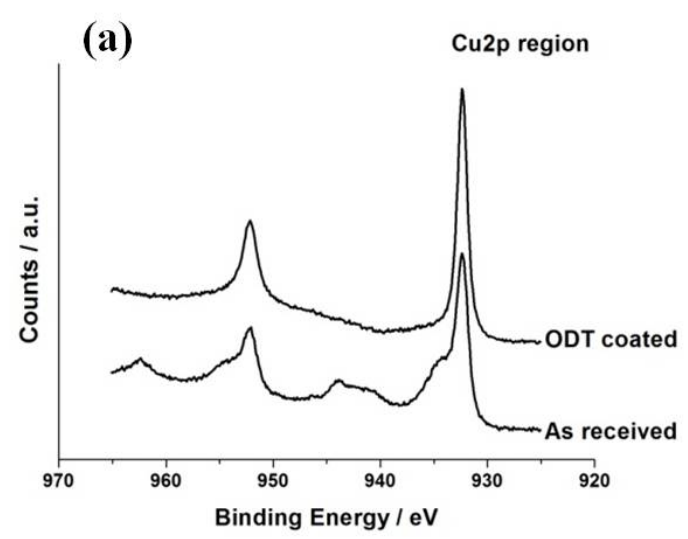

(c)

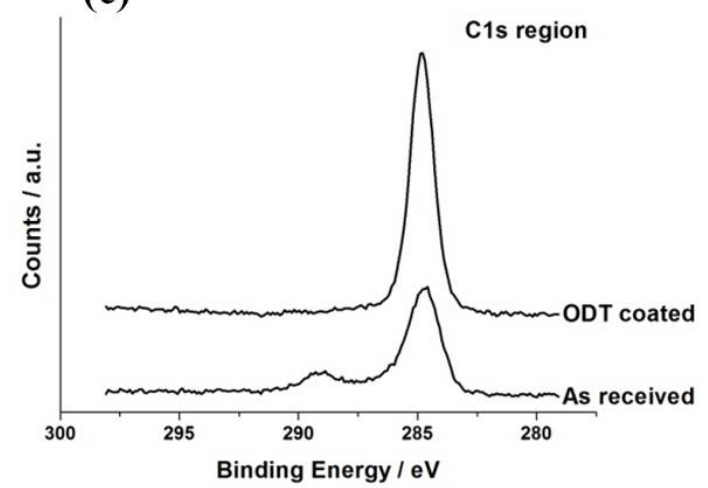

(b)

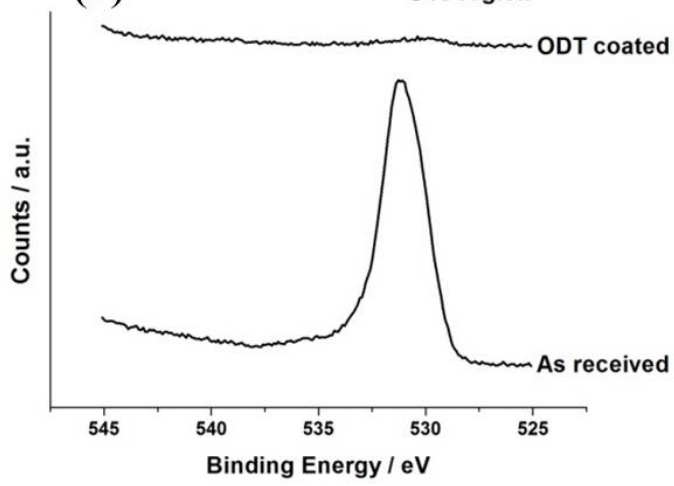

(d)

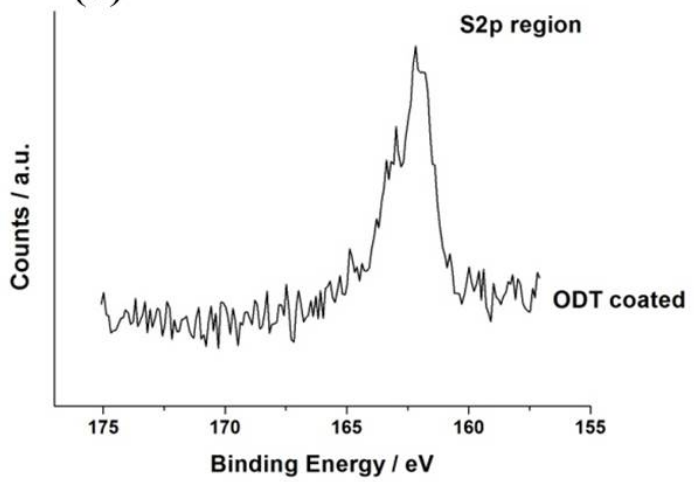

Figure 2: The XPS spectra of ODT-coated and uncoated copper particles: (a) Cu 2p region; (b) O 1s region; (c) C 1s region and (d) S 2p region.

After mixing, the copper particles were well distributed within the HDPE powders, which was beneficial for a continuous electrical pathway to be built during the SLM process. The ODT-coated copper particles were largely spherical in shape with some pores in the surface, while the HDPE powder demonstrated an irregular shape with a relatively smooth surface (Figure 3). 


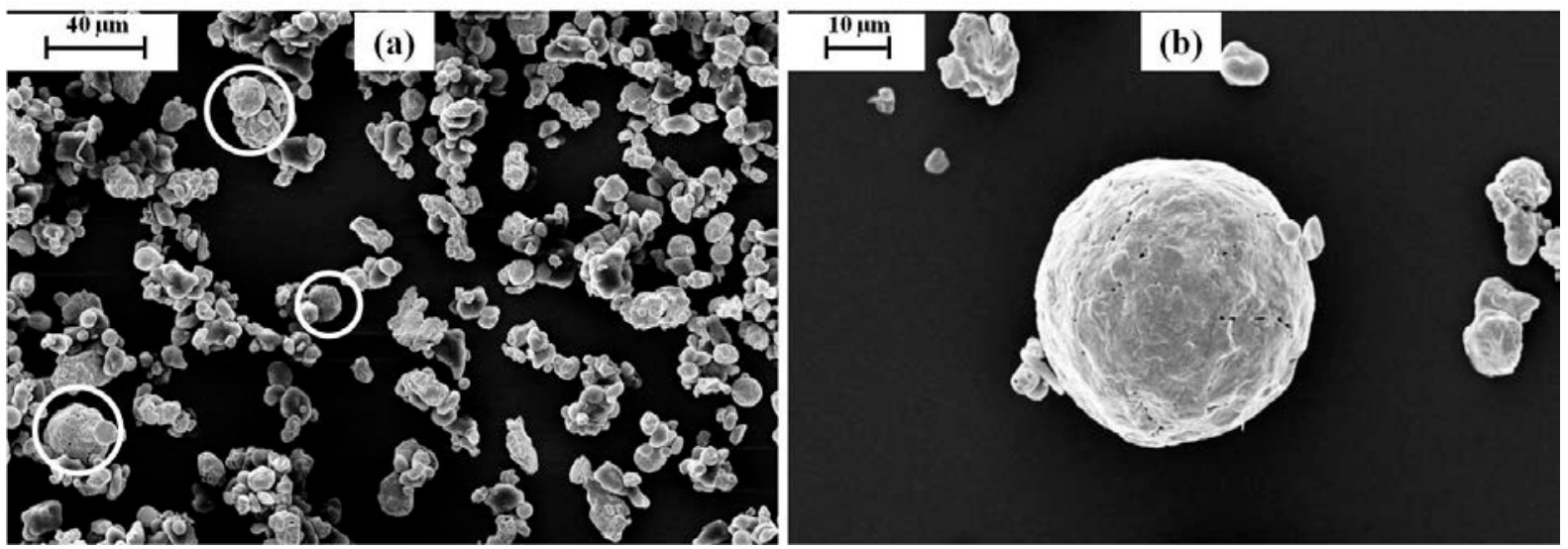

Figure 3: (a) SEM images of the copper/HDPE powder mixture (some copper particles are highlighted using white circles) and (b) magnified copper particle.

\subsection{Electrical Characterisation of Laser Processed Copper/HDPE Mixtures}

The influence of input energy, controlled by laser scanning speed and input power on the electrical resistivity of printed G-s-3/7 and G-s-6/4 tracks was investigated (Figure 4). The electrical resistivity of G-s-3/7 samples decreased when the input power increased from 10 to 20 W, irrespective of the scanning speed (Figure 4 (a)). Poor conductivity was obtained when the input power was $10 \mathrm{~W}$ and the scanning speed was 100 or $120 \mathrm{~mm} / \mathrm{s}$. At $20 \mathrm{~W}$ input power the resistivity of the sample increased with increasing scanning speeds, from $26.6 \pm 0.6 \times 10^{-4} \Omega \mathrm{cm}$ at $80 \mathrm{~mm} / \mathrm{s}$ to $32.6 \pm 2.0 \times 10^{-4} \Omega \mathrm{cm}$ at $120 \mathrm{~mm} / \mathrm{s}$.

The G-s-6/4 samples demonstrated lower resistivity than the G-s-3/7 samples under the same processing conditions. Similarly, the resistivity of G-s-6/4 samples decreased with increasing input power from 10 to $20 \mathrm{~W}$ at all scanning speeds where results were obtained (Figure 4 (b)). The lowest resistivity was reached at $1.9 \pm 0.1 \times 10^{-4} \Omega \mathrm{cm}$ when the input power was $20 \mathrm{~W}$ and the scanning speed was $80 \mathrm{~mm} / \mathrm{s}$ : this value is around 114 times that of pure copper and is largely due to the incomplete densification of the microstructure, as will be described in the next section. Further reducing the scanning speed to $40 \mathrm{~mm} / \mathrm{s}$ resulted in an increase in the 
resistivity to $121 \pm 10 \times 10^{-4} \Omega \mathrm{cm}$, which was thought to be due to overheating. Conversely, at $20 \mathrm{~W}$ input power, increasing the scanning speed to 120 and $140 \mathrm{~mm} / \mathrm{s}$ also increased the resistivity which was thought to be due to insufficient heating.

Related work on laser processed nano-inks (Ko et al., 2008) tried to correlate resistivity with the energy density, which consists of both input power and laser scanning speed. Energy density $\left(E_{d}\right)$ is given by:

$$
E_{d}=\frac{P}{u_{s} a}
$$

where $P$ is input power, $u_{s}$ is scanning speed and $a$ is beam width. However, in this study, there were distinct differences in the resistivity for the following two groups of samples that had the same $E_{d}$ : (1) G-s-6/4-20-80 $\left(1.9 \pm 0.1 \times 10^{-4} \Omega \mathrm{cm}\right)$ and G-s-6/4-30-120 (21.2 $\pm 2.7 \times 10^{-4}$ $\Omega \mathrm{cm}$, Figure 4 (c)), and (2) G-s-6/4-20-60 (5.3 $\left.\pm 0.2 \times 10^{-4} \Omega \mathrm{cm}\right)$ and G-s-6/4-40-120 (dielectric, Figure 4 (c)). This was thought to be due to the damage within the printed tracks when the input power was too high. From a thermodynamic view, if the heat loss rate in the laser-processed material is high enough to dissipate the input energy quickly, the power and scanning speed could be treated as equivalent conditions and the energy density could be used directly (Simchi, 2004). However, for materials that have low thermal conductivity like HDPE, a significant amount of energy would accumulate and store within the surface when a high power is applied, thus leading to overheating. Consequently, the resistivity of samples manufactured using high power was disproportionately higher than that of samples manufactured using low power. 

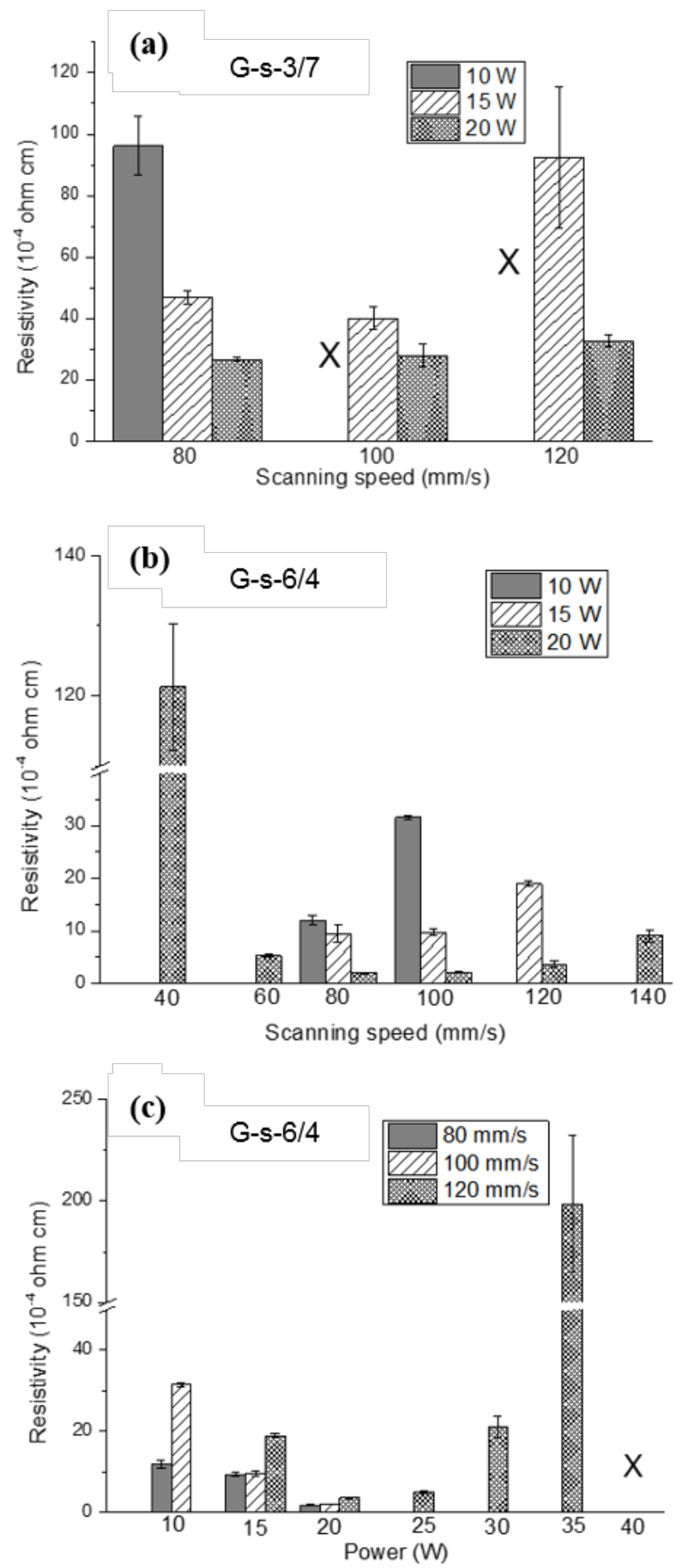

Figure 4: Resistivity of (a) G-s-3/7 samples manufactured using different scanning speeds and input powers; (b) G-s-6/4 samples manufactured using different scanning speeds and input powers; (c) G-s-6/4 samples manufactured using different input powers and scanning speeds. The letter ' $X$ ' denotes the resistivity value is high enough to be recognised as a dielectric material. 


\subsection{Microstructure Characterisation}

The morphologies and microstructures of G-s-3/7 and G-s-6/4 samples were investigated to reveal the laser processing mechanism and how this linked to the resistivity. Figure 5 shows images of the tracks after removal of any loose powder. For G-s-3/7 samples a clear track could be seen following the line of the single scan laser path that consisted of a central region with two clear 'HDPE' lines on either side with a distance between them of around $300 \mu \mathrm{m}$. An increase in the overall track width was found when the input power increased or scanning speed decreased (Figure 5 (b)). The maximum width of the G-s-3/7 samples was $1.06 \mathrm{~mm}$ (Figure 5 (b)), which was achieved at $20 \mathrm{~W}$ and $80 \mathrm{~mm} / \mathrm{s}$ (Figure 5 (a)). This was also the processing condition at which the lowest resistivity was obtained for a G-s-3/7 sample. 
(a)
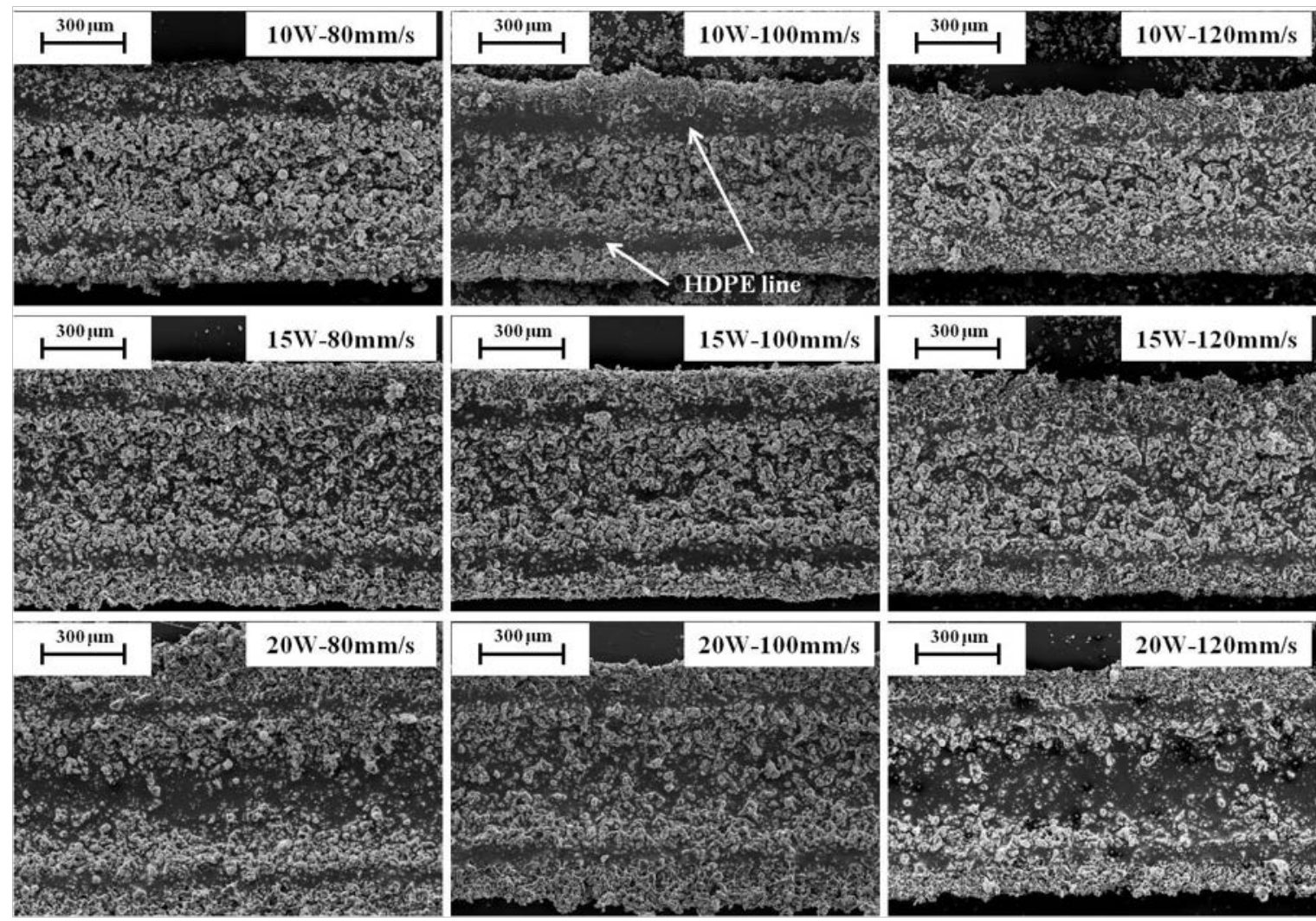

(b)

\begin{tabular}{|c|c|c|c|}
\hline $\begin{array}{l}\text { Scanning } \\
\text { speed }(\mathrm{mm} / \mathrm{s})\end{array}$ & 10 & 15 & 20 \\
\hline 80 & & & \\
\hline 100 & $0.78 \mathrm{~mm}$ & $0.88 \mathrm{~mm}$ & $1.06 \mathrm{~mm}$ \\
\hline 120 & $0.68 \mathrm{~mm}$ & $0.81 \mathrm{~mm}$ & $0.87 \mathrm{~mm}$ \\
\hline
\end{tabular}

Figure 5: G-s-3/7 after laser processing using different scanning speeds and input powers (a) SEM images of the surface morphology and (b) measured average track width from the morphology images.

Higher magnification images of the microstructure of G-s-3/7-15-120 are presented in Figure 6. From the top view, the track could be divided into two zones: the laser direct melting zone in the centre and the heat conduction affected zone towards the edge (Figure 6 (a)). The 
nature of a Gaussian beam is that most of the energy is distributed in the centre and normally the location with $1 / \mathrm{e}^{2}$ of maximum intensity is used to define its spot radius which for this laser is represented in Figure 6 (a) by a circle. The HDPE in the centre was easily melted and/or partially evaporated and the residual copper particles formed nodular structures. Therefore, the thickness in the central region was lower than that at the edge (Figure 6 (b)). An 'HDPE line' could be seen on either side of the central region in the SEM image and appeared relatively smooth with small numbers of copper particles at the surface. In the edge region, the HDPE powder appeared to be melted and flowed generating a bridge-like structure holding the copper particles together and thereby preventing their removal when the loose material was taken off. This could have been due to a small amount of energy that was transferred from the central area to the edge via heat conduction, but also low laser intensity towards the outside of the Gaussian distribution. Additionally, there appeared to be large openings within the microstructure of G-s-3/7-15-120, which could have a negative influence on the electrical properties of the printed track. 


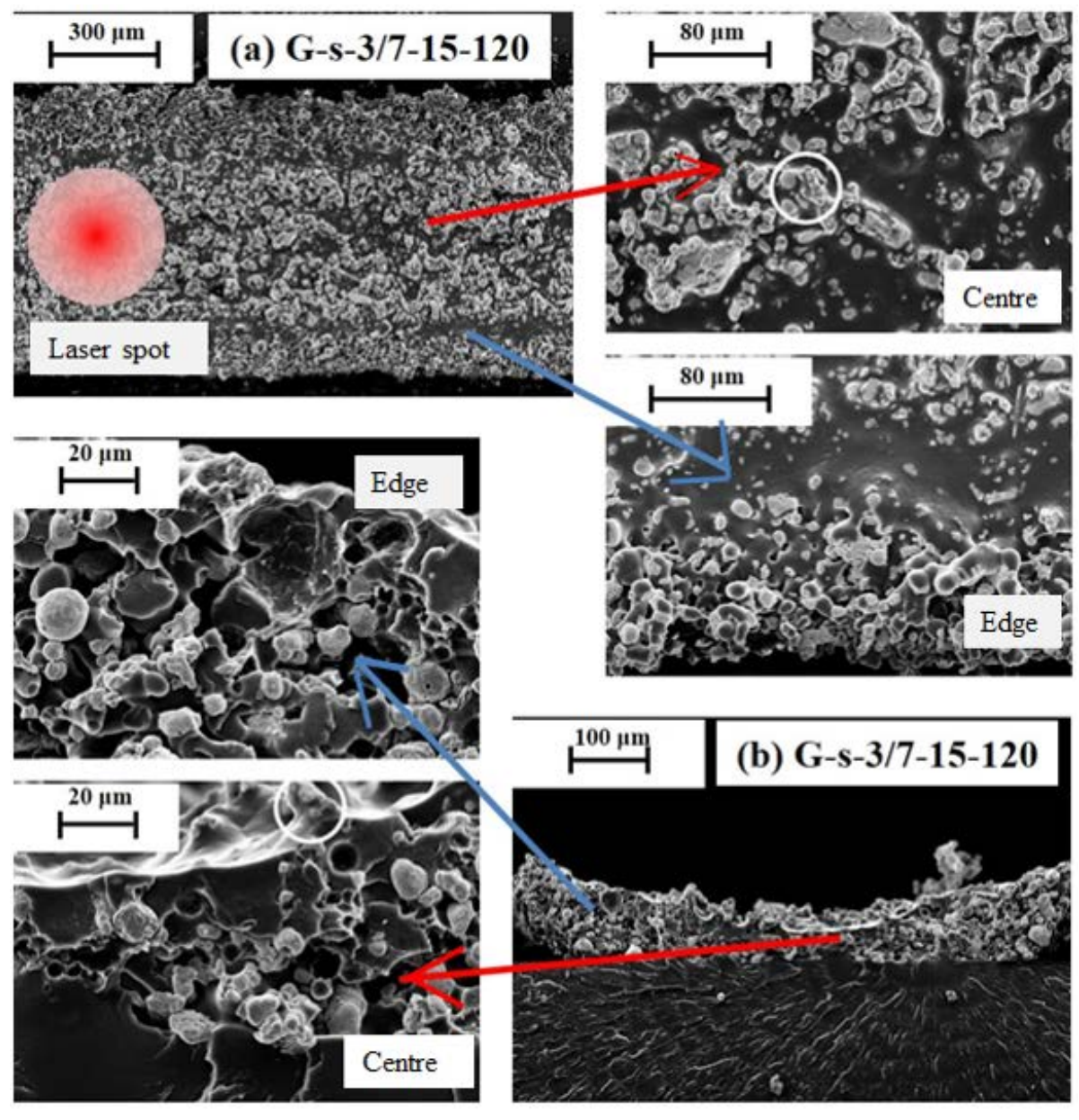

Figure 6: (a) Top view and (b) cross-sectional view SEM images of the microstructures of the G-s-3/7-15-120 sample. Magnified centre and edge regions are indicated by arrows and the nodular-like structure formed by residual copper particles are denoted by white circles.

Figure 7 summarises the morphologies and track widths of the G-s-6/4 samples as a function of laser input power and scanning speed. This demonstrated an open granular structure when a low input power of $10 \mathrm{~W}$ was applied during the process (Figure 7). At $20 \mathrm{~W}$ input power, branch-like structures could be observed in the central region which is thought to be laser direct melting. The width of the branch-like structure region was close to that of the laser spot diameter, which was approximately $300 \mu \mathrm{m}$. If the G-s-6/4 track was processed at a high input energy (e.g. G-s-6/4-40-120), significant melting and balling of the copper occurred 
such that the track appeared to be damaged and the conductive pathway in this region was not continuous: this corresponded with the high resistivity measured for these conditions.
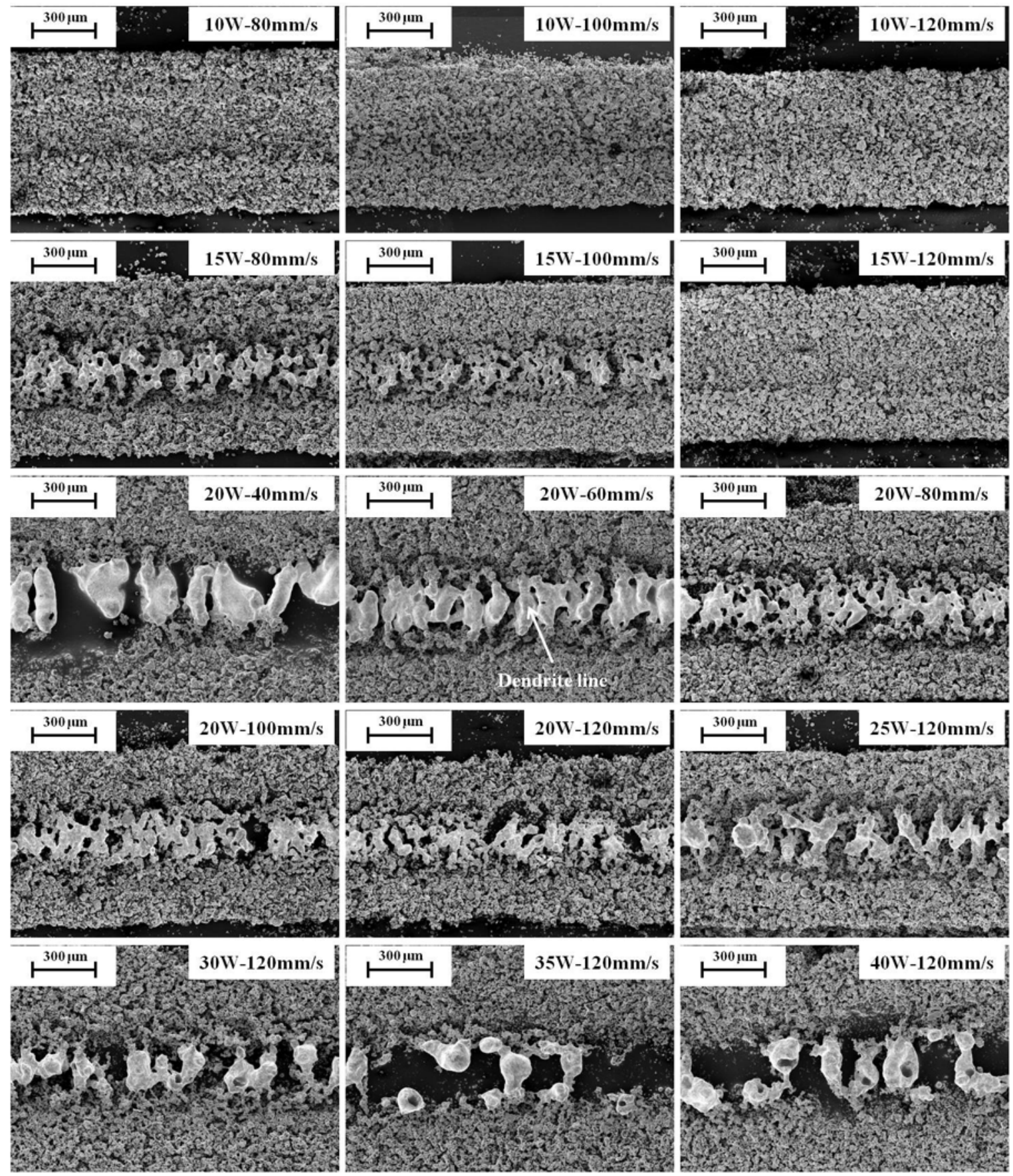

Figure 7: SEM images of the surface morphology of G-s-6/4 samples manufactured using different laser input powers and scanning speeds. 
The sample G-s-6/4-20-120 was selected as a representative of the samples with the branchlike structure in the centre and its microstructure was investigated (Figure 8). HDPE was completely evaporated or degraded in the laser direct melting zone and the copper particles were melted to form a continuous branch-like structure (Figure 8 (a)); in the edge region (heat conduction affected zone and edge of the Gaussian intensity distribution), the melted HDPE connected the copper particles (Figure 8 (b)); there may also have been some joining of the copper particles. There did not appear to be any evidence of the 'HDPE' lines seen in the G-s-3/7 samples. The central branch-like structure was separated from the rest of the track and the base region was bonded to the HDPE substrate through residual melted HDPE. 


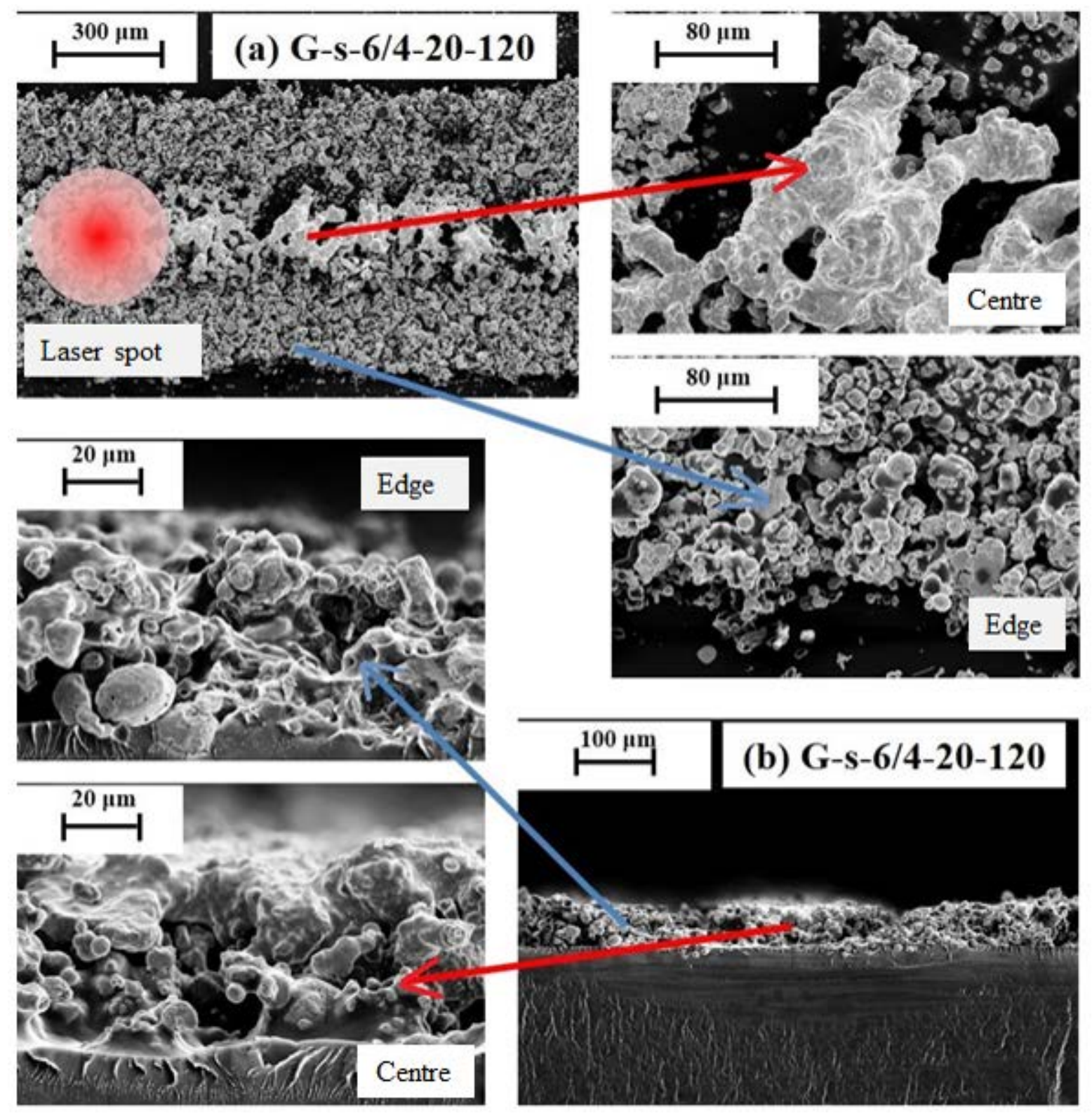

Figure 8: (a) Top view and (b) cross-sectional view SEM images of the microstructures of the G-s-6/4-20-120 sample.

Higher magnification images revealed small bumps inside the consolidated grains of the branch-like structure (Figure 9 (a, b)). The size of the bumps was about 2 5 $\mu \mathrm{m}$, which was smaller than the original copper particle size $(10 \mu \mathrm{m})$ and might result from incomplete melting or liquid melt entrapment of particles during the rapid laser processing. In the heat conduction affected zone, micropores could still be observed on the surface of the copper 
particle, similar to those seen in the original material, due to insufficient heat energy to melt them (Figure 9 (c, d)).

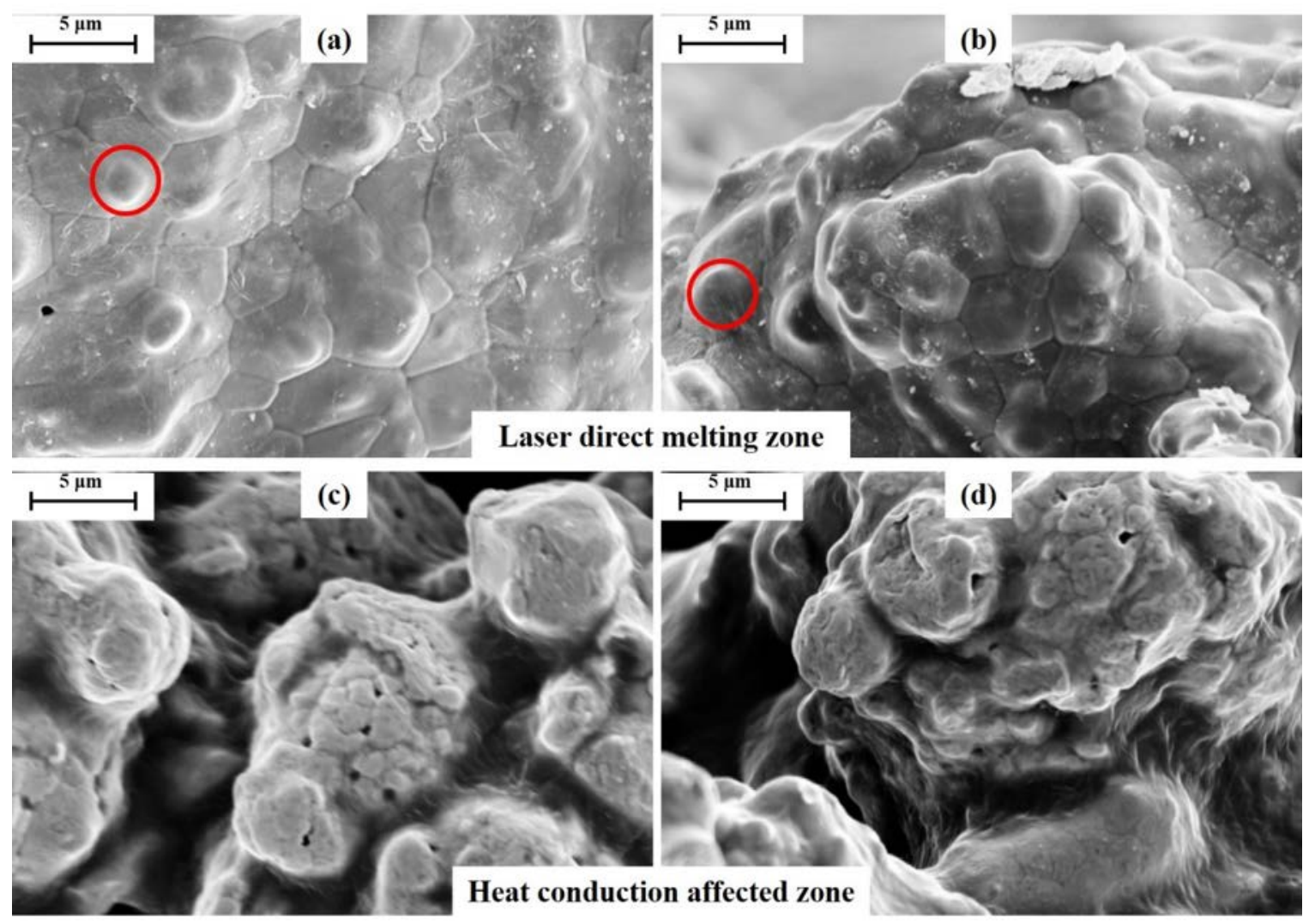

Figure 9: Microstructures of the G-s-6/4-20-120 sample in: (a) top view of the laser direct melting zone (liquid melt entrapment bump is marked with a red circle); (b) cross-sectional view of the laser direct melting zone; (c) top view of the heat conduction affected zone; (d) cross-section view of the heat conduction affected zone.

At 30\% copper content (G-s-3/7), melting/evaporation of the HDPE was the primary phenomenon during the laser processing: a laser beam with a high input energy melted more HDPE powder and increased the overall track width. In general, the microstructure of the samples manufactured using a high input power demonstrated fewer copper particles in the laser direct melting zone (Figure 5 (a)). In contrast, for the higher copper content (G-s-6/4) 
the HDPE particles were evaporated rapidly in the laser direct melting zone and the residual copper particles melted and agglomerated. Overall, the G-s-6/4 samples demonstrated lower resistivity than the G-s-3/7 samples due to the different melting mechanisms and microstructures. For G-s-6/4 samples, the melted copper particles formed a continuous conductive pathway in the middle of the track to facilitate the free movement of electrons within it; the copper particles bonded together at the edge of the track also contributed to the conductivity. However, the conductive pathway for G-s-3/7 samples could only be formed via contacts between copper particles. For both G-s-3/7 and G-s-6/4 samples the outer regions of the tracks were sufficiently bonded to each other and the substrate to resist removal from the surface when the loose powder was removed. This was due to the melting of the HDPE in these regions that bound the particles together thereby providing structural support and potentially enabling the copper particles to be held in contact leading to additional contribution to the electrical conductivity. The levels of resistivity observed are similar to those achieved with silver and copper filled electrically conductive adhesives (Qi et al., 2013) where in that case conductivity is achieved by contact of one particle against another with the surrounding resin providing support for the particles. This indicates that a similar conduction mechanism may be present in some of the structures created here.

Thermal imaging camera temperature profiles recorded from the G-s-6/4-20-120 sample showed the linear scanning of the track (Figure 10). In a very short period, the temperature of the track increased to about $1200{ }^{\circ} \mathrm{C}$ and then dropped back to room temperature (Figure $\mathbf{1 0}$ (b, c)) as the laser spot moved away. The peak temperature value of approximately $1200{ }^{\circ} \mathrm{C}$, is higher than the melting temperature of copper (approx. $1083^{\circ} \mathrm{C}$ ) and supports the presence of the melted structures observed in the G-s-6/4 samples. However, despite this high temperature, the HDPE substrate underneath was undamaged when the copper particles were melted. This is an important advantage of the laser processing system. In this case, a large 
amount of energy was applied to the copper/HDPE mixture layer in a short period. Since the metal phase was discontinuous, the thermal conductivity in the mixture was low and most of the energy flowed to the surrounding environment via surface convection and radiation. The downward energy into the HDPE substrate could only melt the surface and formed an adhesion region between the melted copper track and the substrate.
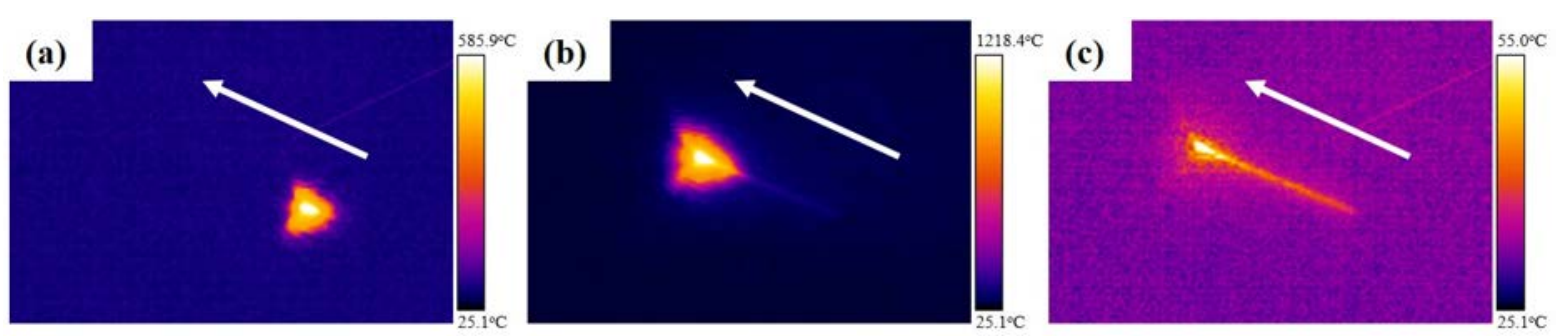

Figure 10: Thermal camera temperature profile of the G-s-6/4-20-120 sample at (a) $t=0.02$ s, (b) $\mathrm{t}=0.22 \mathrm{~s}$; and (c) $\mathrm{t}=0.32 \mathrm{~s}$, the legend for each image varies with the maximum temperature observed.

\subsection{The Effects of Copper Content on the SLM of Copper/HDPE}

Further investigation of the effect of copper content on the structures obtained with fixed laser process parameters was carried out (Figure 11). At $20 \mathrm{~W}$ input power and $120 \mathrm{~mm} / \mathrm{s}$ scanning speed, an overall decrease in resistivity was found when the volume content of copper increased from $30 \%$ to $60 \%$. However, the resistivity did not decrease further when the copper content was above 60\%. Furthermore, it was also found that samples manufactured from 100\% copper powder did not exhibit any conductivity. 


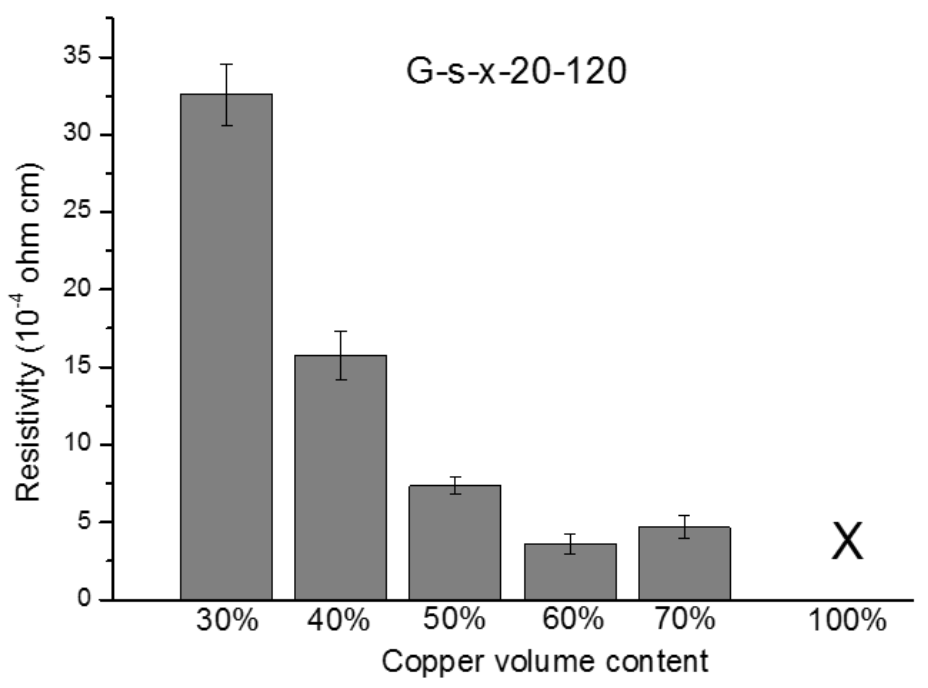

Figure 11: Resistivity of the tracks manufactured using copper/HDPE mixtures at different volume ratios. All samples were manufactured using the single-track-scanning program, at 20 $\mathrm{W}$ input power and $120 \mathrm{~mm} / \mathrm{s}$ scanning speed. $\mathrm{X}$ denotes the resistivity was high enough to be recognised as a dielectric material.

This investigation further demonstrates that at a low copper content, the morphology of the sample was mainly affected by the flow and evaporation of HDPE, where a groove was formed at the centre of the track (Figure 12 (a)). As the copper content increased, there was no longer the formation of a groove and a granular copper structure was created. For low copper content, the melted HDPE helped support the copper particles (Figure 12 (b, c)). However, when the copper content exceeded 50\%, a melted copper track could be observed in the laser direct melting zone, which consisted of branch-like structures (Figure 12 (d, e, f)). 

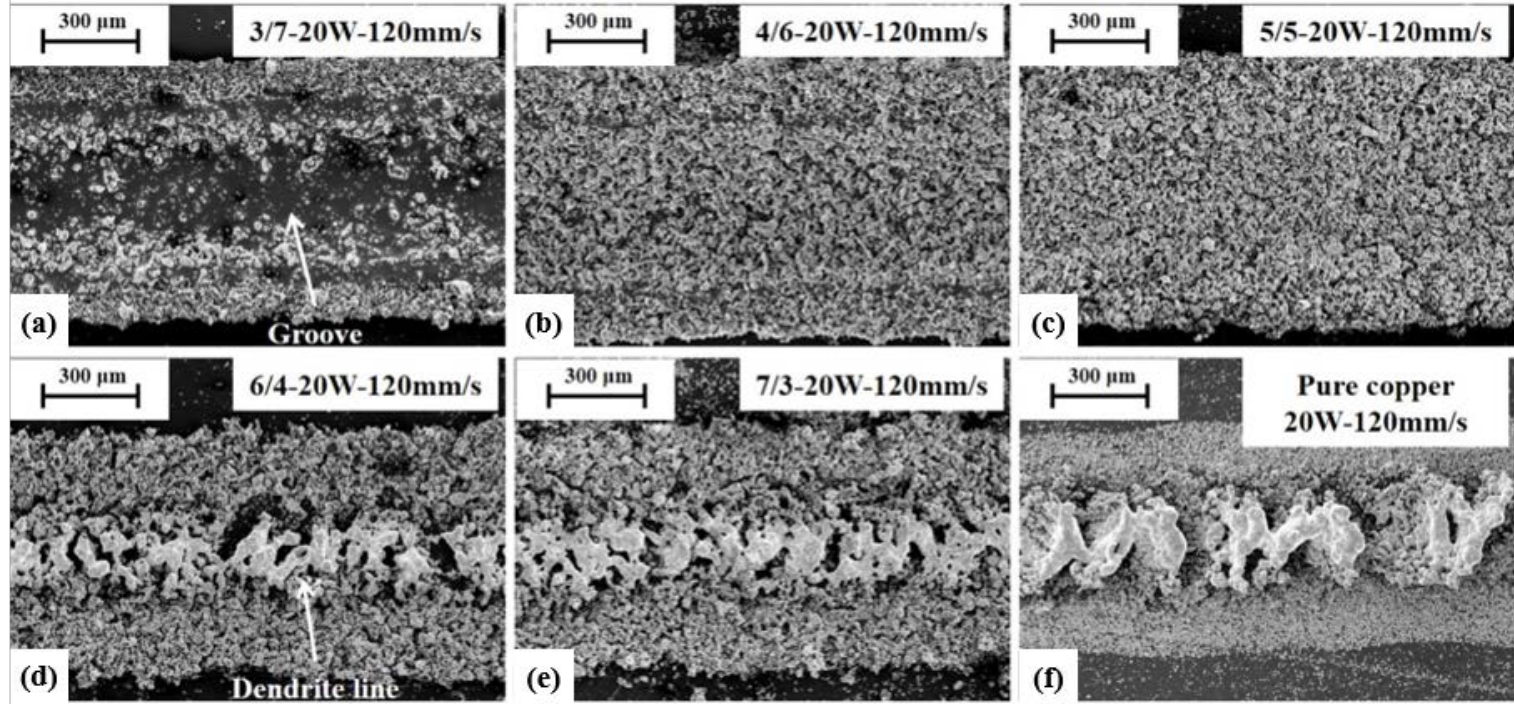

Figure 12: Surface morphology of samples manufactured using copper/HDPE mixtures at different volume ratios: (a) 3/7; (b) 4/6; (c) 5/5; (d) 6/4; (e) 7/3; and (f) pure copper. All samples were manufactured using the single-track-scanning program, at $20 \mathrm{~W}$ input power and $120 \mathrm{~mm} / \mathrm{s}$ scanning speed.

The microstructure of the sample manufactured from 100\% copper demonstrated a transformation from fully melted copper to non-melted copper from the centre to the edge of the track (Figure 13 (a)). Noticeable gaps were found between the melted copper phases causing a discontinuous non-conductive track. The melted track was also separated from the HDPE substrate (Figure 13 (b)). The primary interaction between the copper and HDPE matrix is through van der Waals forces, which are weak and easily broken during, for example, the shrinkage of the HDPE that occurs during the cooling stage, or shrinkage of the copper as the particles melt together. Furthermore, in the molten state the copper will not wet to the underlying HDPE and will tend to flow into spherical structures to reduce the surface tension. Therefore, the adhesion between the melted copper branch-like structure and the HDPE substrate was poor and it was likely to form a discontinuous copper track under this 
condition. In contrast, for the copper/HDPE mixture, part of the HDPE powder was melted and provided an adhesion enhancement between the copper phase and the substrate. With 20 W input power and $120 \mathrm{~mm} / \mathrm{s}$ scanning speed, to achieve the lowest resistivity in the melted track and maintain adhesion to the substrate, it was necessary to mix the copper powder with the HDPE powder with the optimum copper/HDPE volume ratio of 6/4.

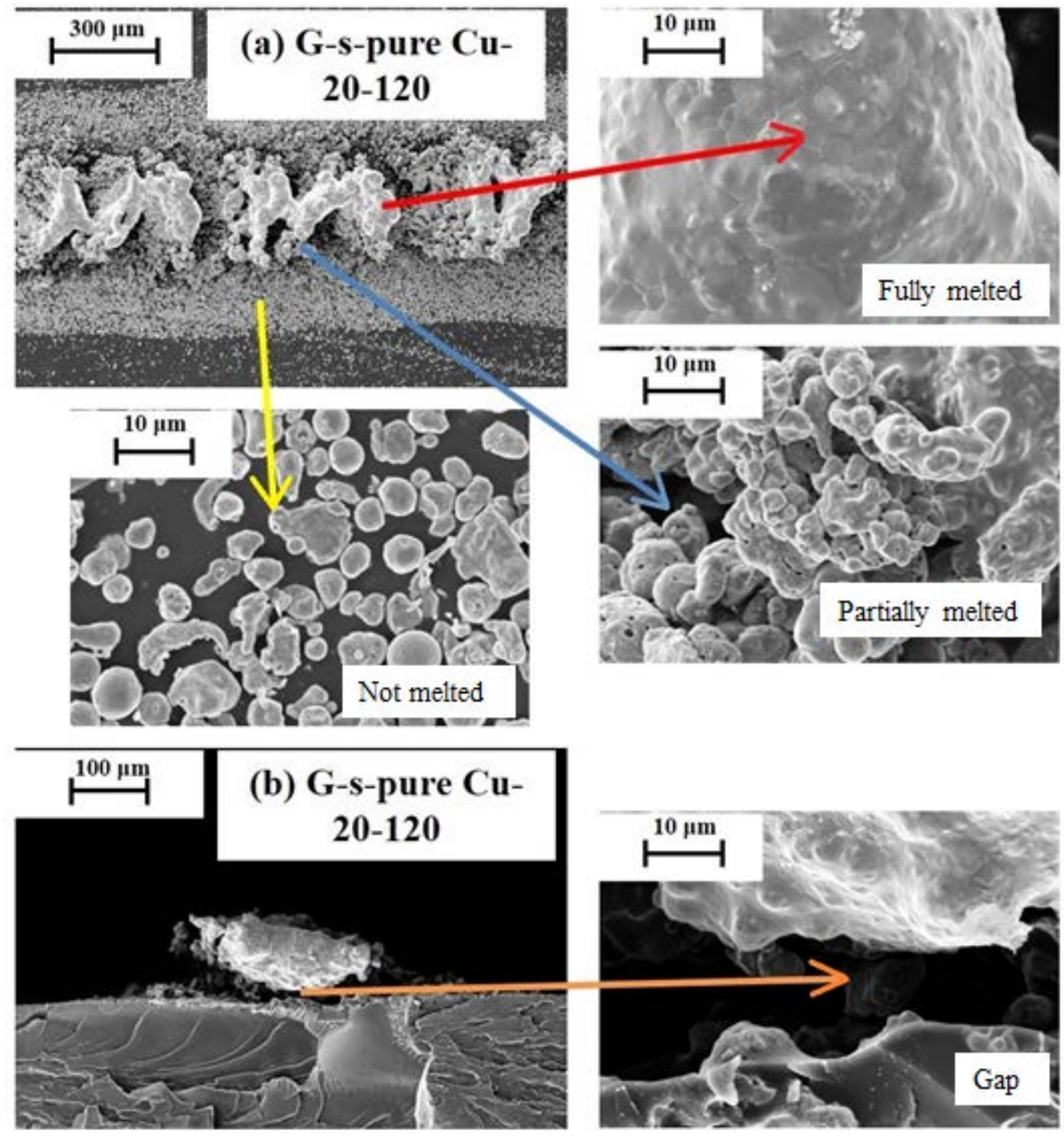

Figure 13: SEM images of the microstructures of the laser processed $100 \%$ copper sample from: (a) top view and (b) cross-sectional view. 


\subsection{The Effects of Different Scanning Programs on the SLM of Copper/HDPE}

Figure 14 shows the resistivity results for samples scanned using the raster pattern with different laser input power. The lowest resistivity of $0.35 \pm 0.04 \times 10^{-4} \Omega \mathrm{cm}$ (approximately 21 times that of pure copper) was achieved for the G-r-6/4-20-80 sample (Figure 14). It should be noted that the single line and raster scanning programs cannot be directly compared for the same laser input energy as due to the pattern that was followed the total energy delivered at the sample was different. For the raster-scanning program with $0.2 \mathrm{~mm}$ width, $0.1 \mathrm{~mm}$ scan spacing, the total laser spot movement, $L$ can be calculated as:

$$
L=0.2 *\left(\frac{l_{p}}{0.1}+1\right) \approx 2 l_{p}
$$

where $l_{p}$ was the overall length of the machined track. Based on these dimensions, the time to process unit length of the track will be the same when the raster-scanning program is twice the scanning speed of the single-track program. Therefore, two groups of samples can be compared: (1) G-s-6/4-20-40 $\left(121 \pm 10 \times 10^{-4} \Omega \mathrm{cm}\right)$ to G-r-6/4-20-80 $\left(0.35 \pm 0.04 \times 10^{-4} \Omega \mathrm{cm}\right)$;

and (2) G-s-6/4-20-60 (5.3 $\left.\pm 0.2 \times 10^{-4} \Omega \mathrm{cm}\right)$ to G-r-6/4-20-120 $\left(0.79 \pm 0.03 \times 10^{-4} \Omega \mathrm{cm}\right)$. In both cases, despite the same power and time to process the tracks, the samples manufactured using the raster-scanning program demonstrated lower resistivity compared to those manufactured using the single-track-scanning program. 


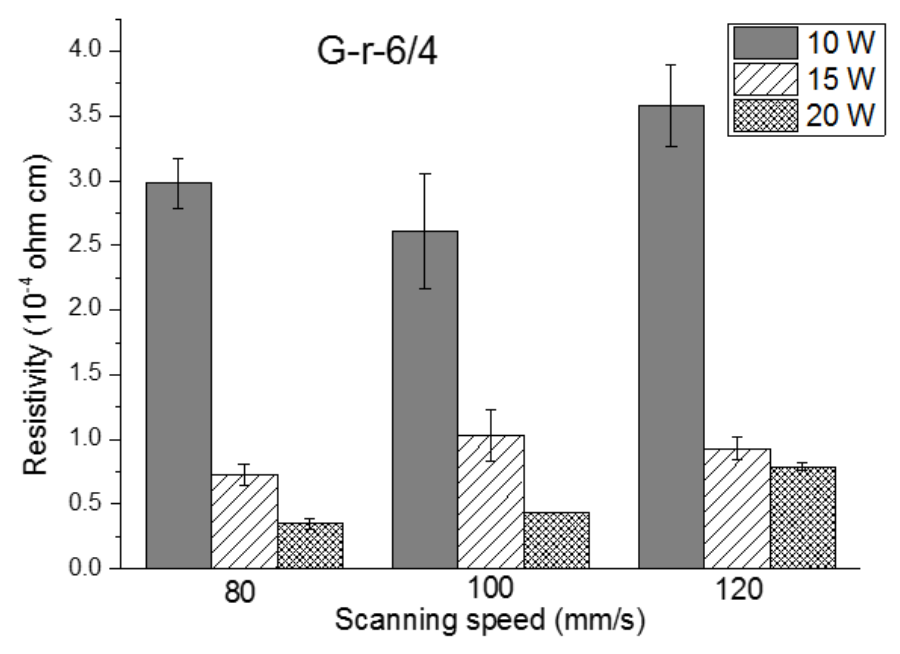

Figure 14: Resistivity of G-r-6/4 samples at different laser scanning speeds and input powers.

The G-r-6/4 samples are shown in Figure 15. Due to the raster scan pattern, for the same power and scan speed, these tracks were wider than those produced with a single line scan (Figure 16). The Gaussian beam has a non-uniform intensity distribution, where most of the energy is concentrated in the centre. Therefore, the copper melting only occurred in the central region of the beam spot. In a single-track-scanning program, the copper phase was more significantly melted when increasing the input power or decreasing the scanning speed: however, this could damage the printed track causing poor conductivity. However, during the raster-scanning program a larger region was exposed to the laser and the overall energy distribution on the track surface was more uniform due to the movement of the beam. It therefore generated a larger melted region without damaging the track and effectively reduced the resistivity. 
(a)
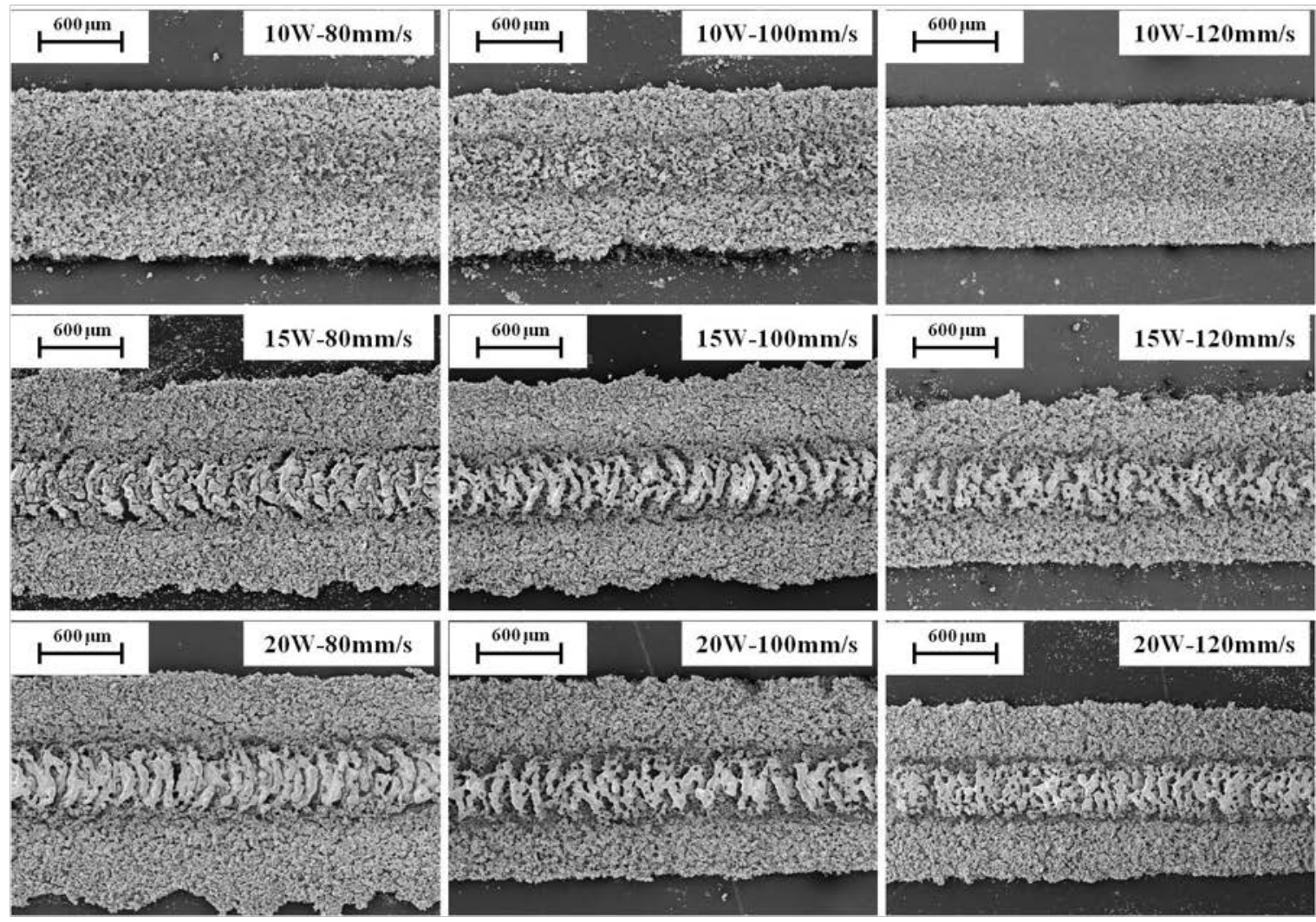

(b)

\begin{tabular}{|c|c|c|c|c|c|c|}
\hline $\begin{array}{l}\text { Pcanning } \\
\text { speed (mm/s) }\end{array}$ & \multicolumn{2}{|c|}{10} & \multicolumn{2}{c|}{15} & \multicolumn{2}{c|}{20} \\
\hline & \multicolumn{2}{|c|}{ (W) } & & \multicolumn{2}{c|}{} \\
\hline 80 & $1.20 \mathrm{~mm}$ & $0.76 \mathrm{~mm}$ & $1.51 \mathrm{~mm}$ & $0.79 \mathrm{~mm}$ & $1.61 \mathrm{~mm}$ & $0.93 \mathrm{~mm}$ \\
\hline 100 & $1.16 \mathrm{~mm}$ & $0.65 \mathrm{~mm}$ & $1.41 \mathrm{~mm}$ & $0.77 \mathrm{~mm}$ & $1.42 \mathrm{~mm}$ & $0.82 \mathrm{~mm}$ \\
\hline 120 & $1.01 \mathrm{~mm}$ & $0.62 \mathrm{~mm}$ & $1.20 \mathrm{~mm}$ & $0.73 \mathrm{~mm}$ & $1.26 \mathrm{~mm}$ & $0.75 \mathrm{~mm}$ \\
\hline
\end{tabular}

Figure 15: G-r-6/4 samples after laser processing. (a) SEM images of the surface morphology and (b) the measured track widths from the morphology images. 

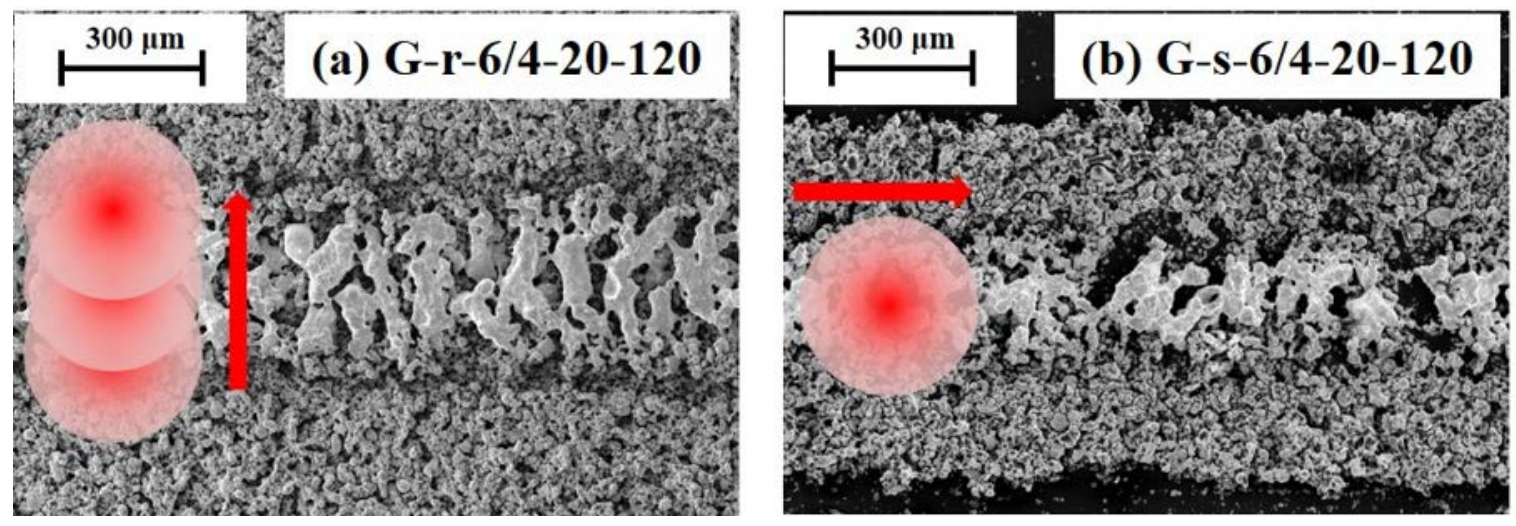

Figure 16: Comparison between (a) the G-r-6/4-20-120 sample and (b) the G-s-6/4-20-120 sample, where the spot and arrow represent the Gaussian beam and its scanning direction, respectively.

\subsection{Additive Manufacturing of Multi-Layer 3D Circuits}

Based on the obtained results, a 2D timer circuit consisting of copper/HDPE tracks on an HDPE substrate was first manufactured following the process route shown in figure 1, but using the laser to trace a complete circuit pattern instead of single lines (Figure 17). Surface mount components were attached to the copper tracks using silver filled conductive adhesive (Gwent Group, UK) that was deposited manually on the surface and cured using a hotplate inside a sealed glovebox (with Ar atmosphere) for 0.5 hour at $80{ }^{\circ} \mathrm{C}$ thereby avoiding damage to the temperature sensitive HDPE substrate. The circuit was connected to a power supply and operated correctly. 


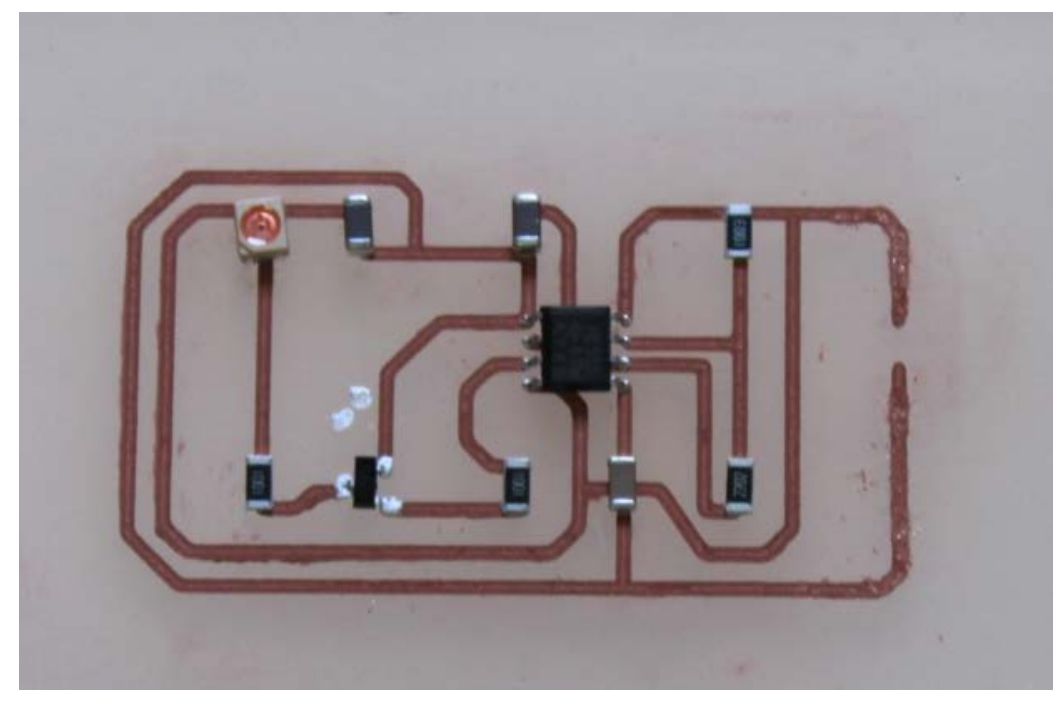

Figure 17: 2D timer circuit manufactured using SLM on an HDPE substrate.

The same timer circuit was then re-designed to a 3D embedded circuit system with two circuit layers interconnected with vertical vias (Figure 18 (a)). The embedded circuit was manufactured using SLM with HDPE as the matrix material and copper/HDPE as the conductive tracks. A powder layer thickness of $150 \mu \mathrm{m}$ was used and G-r-6/4-20-120 was selected as the processing condition for manufacturing the conductive tracks from the copper/HDPE powder mixture. The manufacturing process is shown in Figure 18 (b) and began with the manufacture of a HDPE substrate with the following scanning conditions: 10 W power, $240 \mathrm{~mm} / \mathrm{s}$ scanning speed, $0.2 \mathrm{~mm}$ scan spacing. The substrate was then fixed on a steel back plate to prevent thermal warping during laser processing (Figure 19 (a)). The copper/HDPE powder mixture was deposited using a blade and then selectively laser-melted to create the first circuit layer, followed by removal of the un-melted powder (Figure 19 (b)). Another layer of HDPE powder was then deposited and subsequently laser-melted to create the HDPE supporting layer (Figure 19 (c)). This process was repeated until the multiple layer circuit system was built. During this process vias were also created to join layers by building up $1 \mathrm{~mm}$ x $1 \mathrm{~mm}$ square copper layers. 


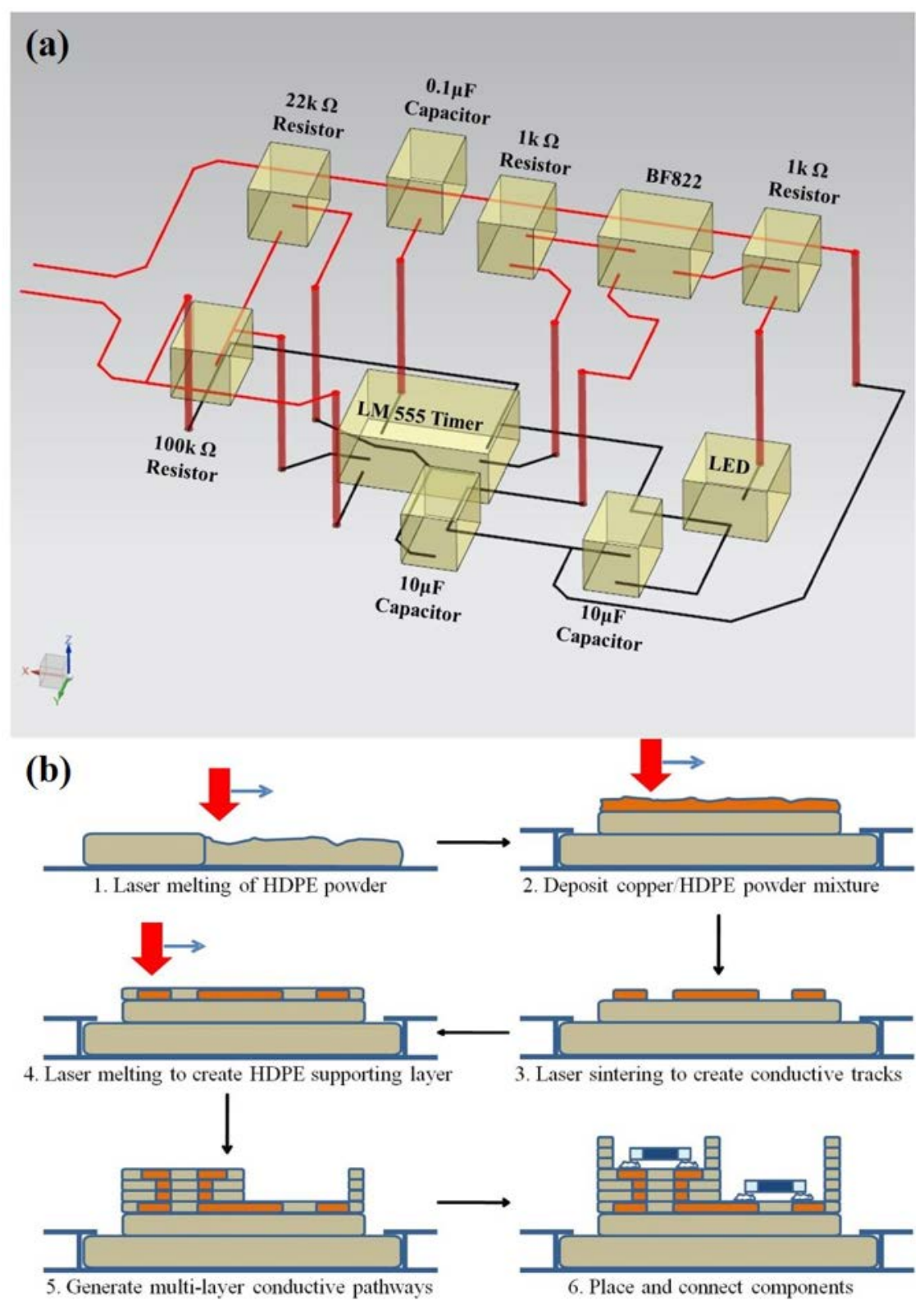

Figure 18: Schematic diagrams of (a) a 3D embedded timer circuit, where the black and red lines represent the $1^{\text {st }}$ and $2^{\text {nd }}$ circuit layer, respectively; and (b) different steps during the SLM process to manufacture a 3D timer circuit with dissimilar materials (cross-section view). 

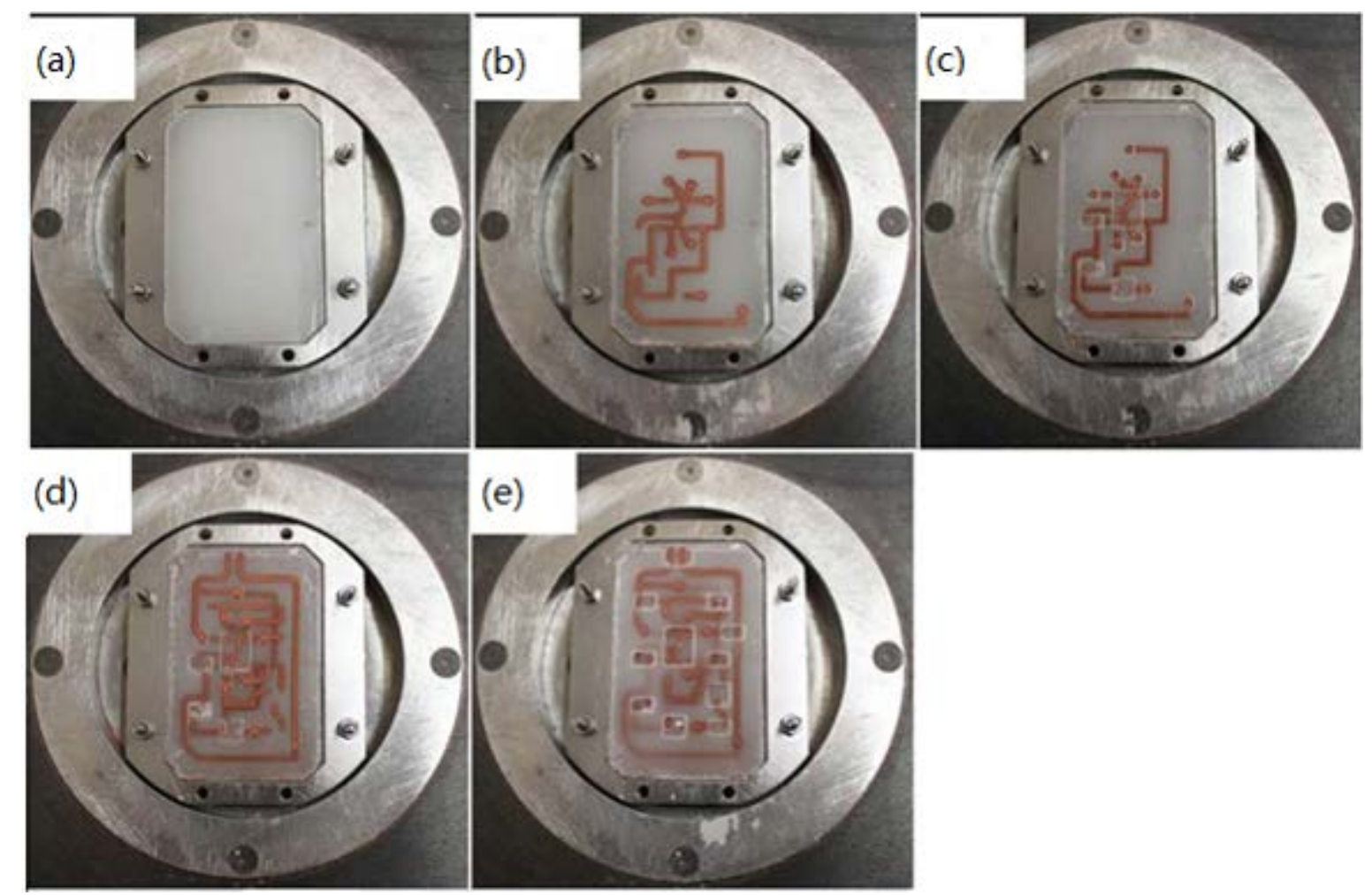

Figure 19: Different steps during the SLM process to manufacture a 3D timer circuit with dissimilar materials: (a) manufacturing of the HDPE substrate; (b) manufacturing of the $1^{\text {st }}$ circuit layer; (c) manufacturing of the vertical vias and HDPE supporting layers; (d) manufacturing of the $2^{\text {nd }}$ circuit layer; (e) manufacturing of embedded circuit system.

Electronic components were placed in the designed slots and connected with the copper tracks using silver conductive adhesive which was cured using the same method as for the $2 \mathrm{D}$ circuit described above. Multiple circuit layers and the square interconnections between them were demonstrated. The tracks were clearly separated from each other and the size of the designed slots were suitable for incorporating electronic components. To check the performance of the manufactured circuit, a voltage of $5 \mathrm{~V}$ was applied and the LED light was seen to flash (Figure 20). 
The results demonstrated the success of 3D circuit manufacturing using SLM processing of two different powder materials. Further development of this technology into a production system will require the establishment of methods to allow sequential deposition, removal and separation of the powders for reuse, which is an area where techniques have already been proposed (Chivel, 2016). Further work is also needed to determine the reliability and fully characterise the performance of the tracks and vias including their adhesion to the substrate and potential for use in high frequency devices and as antennas. The resistivity and dimensions of the tracks created in this work do not meet the levels of PCB manufacture where linewidths of $50 \mu \mathrm{m}$ with thicknesses of $17 \mu \mathrm{m}$ are attainable. However, this technology offers the opportunity to create fully 3D embedded electronic structures and further work is underway to improve the conductivity and feature sizes.

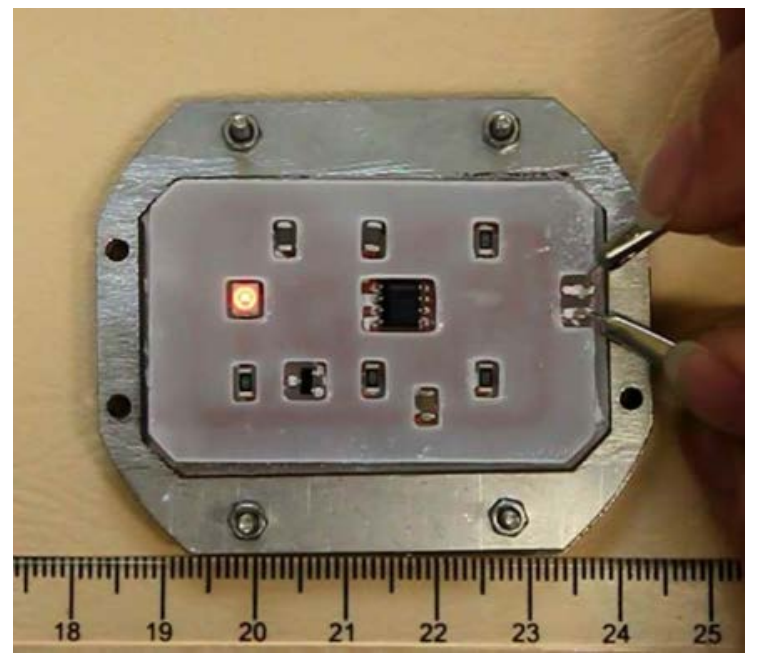

Figure 20: Functional testing of 3D circuit showing the LED illuminated.

\section{Conclusion}

This study has demonstrated the capability of processing copper/HDPE powders using SLM technology to build conductive tracks within a 3D part. The effects of $\mathrm{CO}_{2}$ laser input energy 
comprising input power and scanning speed on the resistivity of copper tracks were investigated to identify the optimum processing conditions. Lowest resistivity was achieved when the input power was $20 \mathrm{~W}$ and scanning speed was $80 \mathrm{~mm} / \mathrm{s}$. Processing using higher input power or lower scanning speed resulted in HDPE evaporation and a granular structure was therefore generated, compromising the conductivity of the printed tracks.

The mechanism of conductivity at different copper contents was also investigated based on the microstructure of the printed tracks. At 30\% copper content, a continuous electrical pathway was formed due to contact between copper particles. However, this caused localised discontinuity of the conductive phase resulting in poor conductivity. The copper particles melted forming a more continuous electrical pathway when the copper content increased to $60 \%$. Further increasing the copper content to $100 \%$ however, resulted in poor adhesion between the copper track and the HDPE substrate.

Compared to a single-track-scanning program, the overall energy distribution on the surface of a printed track was more uniform when it was manufactured using a raster-scanning program where a larger melted region was generated without damaging the track. This effectively reduced the track resistivity to $0.35 \pm 0.04 \times 10^{-4} \Omega \mathrm{cm}$ with the following conditions: 6/4 copper/HDPE powder ratio, $20 \mathrm{~W}$ laser input power, $80 \mathrm{~mm} / \mathrm{s}$ scanning speed, and rasterscanning program.

Based on the obtained results, 2D and 3D timer circuits were manufactured using copper/HDPE as the conductive-track material and HDPE as the substrate material. The performance test manifested that the circuits were successful. This study has shown the processability of copper/HDPE powder in SLM technology and demonstrated the capability of manufacturing dissimilar materials using AM to build a 3D functional electrical system. 


\section{Acknowledgement}

The authors would like to thank the Wolfson School and Materials Research School, Loughborough University for financial support of $\mathrm{PhD}$ Scholarships and Laser Optical Engineering Ltd for additional financial support. The assistance of the staff and analysis facilities of the Loughborough Materials Characterisation Centre (LMCC) is also gratefully acknowledged.

\section{References}

Bai, J., Zhang, B., Song, J., Bi, G., Wang, P. and Wei, J., 2016. The effect of processing conditions on the mechanical properties of polyethylene produced by selective laser sintering. Polymer Testing, 52, pp.89-93.

Caulfield, B., McHugh, P.E. and Lohfeld, S., 2007. Dependence of mechanical properties of polyamide components on build parameters in the SLS process. Journal of Materials Processing Technology, 182(1), pp.477-488.

Chen, J.Y. and Young, W.B., 2013. Two-component injection molding of molded interconnect devices. In Advanced Materials Research (Vol. 628, pp. 78-82). Trans Tech Publications.

Chivel, Y., 2016. New approach to multi-material processing in selective laser melting. Physics Procedia, 83, pp.891-898. 
Cui, W., Lu, W., Zhang, Y., Lin, G., Wei, T. and Jiang, L., 2010. Gold nanoparticle ink suitable for electric-conductive pattern fabrication using ink-jet printing technology. Colloids and Surfaces A: Physicochemical and Engineering Aspects, 358(1), pp.35-41.

D'aveni, R.A., 2013. 3-D printing will change the world. Harvard business review, 91(3), pp.34-35.

Etienne, B.T., Sandborn, P., 2007. Optimizing Embedded Passive Content in Printed Circuit Boards, IEEE Trans. Electronics Packaging Manufacturing, 30(4), pp. 246-257.

Goodridge, R.D., Tuck, C.J. and Hague, R.J.M., 2012. Laser sintering of polyamides and other polymers. Progress in Materials Science, 57(2), pp.229-267.

Hutt, D.A. and Liu, C., 2005. Oxidation protection of copper surfaces using self-assembled monolayers of Octadecanethiol. Appl. Surf. Sci. 252, pp. 400-411.

Ko, S.H., Pan, H., Grigoropoulos, C.P., Luscombe, C.K., Fréchet, J.M. and Poulikakos, D., 2007. All-inkjet-printed flexible electronics fabrication on a polymer substrate by lowtemperature high-resolution selective laser sintering of metal nanoparticles. Nanotechnology, 18(34), p.345202.

Ko, S.H., Pan, H., Grigoropoulos, C.P., Fréchet, J.M., Luscombe, C.K. and Poulikakos, D., 2008. Lithography-free high-resolution organic transistor arrays on polymer substrate by low energy selective laser ablation of inkjet-printed nanoparticle film. Applied Physics A, 92(3), pp.579-587.

Laibinis, P.E. and Whitesides, G.M., 1992. Self-assembled monolayers of n-alkanethiolates on copper are barrier films that protect the metal against oxidation by air. J. Am. Chem. Soc. 114, pp. 9022-9028. 
Liu, Z.H., Zhang, D.Q., Sing, S.L., Chua, C.K., and Loh, L.E., 2014. Interfacial characterization of SLM parts in multi-material processing: Metallurgical diffusion between 316L stainless steel and C18400 copper alloy. Materials characterization, 94, pp.116-125.

Lopes A.J., MacDonald E., and Wicker R., 2012. Integrating stereolithography and direct print technologies for 3D structural electronics fabrication. Rapid Prototyping Journal, 18/2, pp.129-143.

Mironov, V.S., Kim, J.K., Park, M., Lim, S. and Cho, W.K., 2007. Comparison of electrical conductivity data obtained by four-electrode and four-point probe methods for graphite-based polymer composites. Polymer testing, 26(4), pp.547-555.

Mun, S., Yun, S., Jung, H. and Kim, J., 2012. Sintering condition effect on the characteristics of ink-jet printed silver pattern on flexible cellulose paper. Current Applied Physics, 12, pp.e10-e13.

Park, B.K., Kim, D., Jeong, S., Moon, J. and Kim, J.S., 2007. Direct writing of copper conductive patterns by ink-jet printing. Thin Solid Films, 515(19), pp.7706-7711.

Qi, S., Vaidhyanathan B., Hutt D., 2013. Conventional and microwave-assisted processing of Cu-loaded ICAs for electronic interconnect applications. Journal of Materials Science, 48(20), pp.7204-7214

Sanchez-Romaguera, V., Madec, M.B. and Yeates, S.G., 2008. Inkjet printing of 3D metalinsulator-metal crossovers. Reactive and Functional Polymers, 68(6), pp.1052-1058.

Siegel A.C., Phillips S.T., Dickey M.D., Lu N., Suo Z., and Whitesides G.M., 2010. Foldable printed circuit boards on paper substrates. Advanced Functional Materials, 20, pp.28-35. 
Simchi, A., 2004. The role of particle size on the laser sintering of iron powder. Metallurgical and Materials Transactions B, 35(5), pp.937-948.

Tahir, D. and Tougaard, S., 2012. Electronic and optical properties of $\mathrm{Cu}, \mathrm{CuO}$ and $\mathrm{Cu}_{2} \mathrm{O}$ studied by electron spectroscopy. Journal of Physics: Condensed Matter, 24(17), p.175002. 